$\%$ N0.21-008 $01 / 2021$

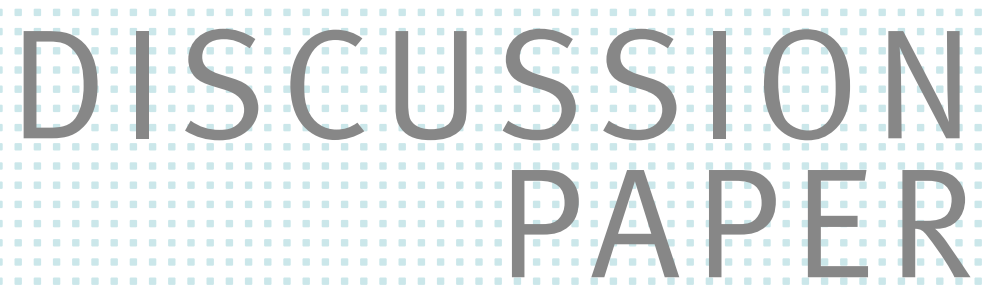

/ / ANNA THERESA BÜHRLE

\title{
Do Tax Loss Restrictions Distort Venture Capital Funding of Start-Ups?
}




\title{
Do Tax Loss Restrictions Distort Venture Capital Funding of Start-ups?
}

\author{
Anna Theresa Bührle* \\ ZEW and University of Mannheim
}

-This version: January $13^{\text {th }}, 2021$ -

\begin{abstract}
:
Anti-tax loss trafficking rules disallow the use of loss carryforwards after a change in ownership or activity (such as significant changes in turnover, employment, or the product portfolio). This restriction could threaten accumulated loss carryforwards of start-ups. Accounting for the increased risk and reduced return on their investment, VC investors could reduce their funding. I analyze whether the venture capital (VC) funding of start-ups in Europe is affected by these regulations. I base my empirical analysis on several case studies and a panel analysis covering VC-funded companies in the EU28 Member States from 1999 to 2014. My findings suggest that strict anti-tax loss trafficking rules indeed impair VC funding. Especially more mature companies and companies in high-tech industries are affected.
\end{abstract}

JEL: M13, G24, H25

Keywords: Venture capital, taxes, loss carryforward, start-ups, anti-tax loss trafficking

\section{Acknowledgments:}

I gratefully acknowledge helpful comments from Christoph Spengel, Jost Heckemeyer and Philipp Dörrenberg. I also received valuable feedback from the participants at the brown-bag seminar at the University of Mannheim, the joint workshop at the University of Brescia, the MannheimTaxation Campus Meeting in December 2019, the $76^{\text {th }}$ Annual Congress of the IIPF and the $113^{\text {th }}$ NTA Annual Conference on Taxation. I benefitted from individual conversations with multiple colleagues at the ZEW and the University of Mannheim. I am grateful to the researchers at the Polytechnic University of Milan and InvestEurope for providing me with data on venture capital investments used in this study. This work received financial support from the Leibniz ScienceCampus MannheimTaxation and RISIS2 (Research Infrastructure for Innovation Policy Studies 2) funded by the European Union's Horizon 2020 research and innovation program under the grant number $n^{\circ} 824091$.

\footnotetext{
${ }^{*}$ Centre for European Economic Research (ZEW), L7 1, D-68131 Mannheim, Germany, theresa.buehrle@zew.de
} 
Start-ups contribute to the creation of new jobs and are considered an essential driver of innovation (Coad, Segarra, \& Teruel, 2016; Haltiwanger, Jarmin, \& Miranda, 2013; Lawless, 2014; Van Praag \& Versloot, 2007). However, they often suffer from credit constraints due to a lack of sufficient collateral (Carpenter \& Petersen, 2002b, 2002a; Cosh, Cumming, \& Hughes, 2009; Da Rin, Nicodano, \& Sembenelli, 2006). Venture capital (VC) funds bridge the funding gap with private equity (PE) investment. They support entrepreneurs in their start-up phase, aiming to exit after several years via a sale of the company or an initial public offering (IPO) (Schwienbacher, 2008). Restrictions on the transfer of tax losses after the exit of investors have been criticized as one deterrence for VC funding. In particular, this claim applies to companies carrying substantial amounts of start-up losses. In this paper, I investigate whether VC investors indeed reduce the financing of start-ups in response to anti-tax loss trafficking rules.

For tax purposes, most countries treat losses asymmetrically. Profits are taxed immediately, whereas losses can only be deducted against past profits (loss carryback, LCB) or future profits (loss carryforward, LCF). Initially, most start-ups invest in their projects without generating corresponding income, resulting in an overall loss. Empirical evidence confirms that LCFs tend to be concentrated among young firms (Cooper \& Knittel, 2006). These LCFs can only be set off at a later stage when the start-up turns profitable. As such, the tax assets are valuable because they can reduce future tax liabilities.

In some instances, such as a substantial change in activity or ownership, anti-tax loss trafficking rules can lead to the forfeiture of accumulated LCFs. What constitutes a harmful change depends on the country-specific regulations. Substantial changes in ownership are often defined as changes above $50 \%$ or changes in control. Changes in activity can be tied to financial statement figures or target markets, or a general reference that provides a lot of flexibility in interpretation. Legislators aim to counter so-deemed abusive transactions, where bankrupt corporate shells are bought. These corporations do not have noteworthy economic activity or prospects. Other profitable companies acquire them for no reason other than their LCFs. However, the regulations might also, unintentionally, affect transactions with sound economic reasons. Broadly speaking, investors might refrain from partaking in an investment or acquisition if they risk endangering valuable LCFs. More particular, the restrictions could affect start-ups that are only just beginning to build up their business (Bührle \& Spengel, 2020).

These tax loss provisions might prevent investors from funding a start-up's undertakings if losses have accumulated over time that may become worthless due to the regulation (Haufler, 
Norbäck, \& Persson, 2014). When venture capitalists exit, the start-up can still carry substantial amounts of LCFs. The exiting investors will incorporate the value of the LCF in their price calculations. However, if buyers cannot use the losses after the acquisition, they will not be willing to pay for them, leading to a different valuation of the start-up (Sureth-Sloane \& Vollert, 2009). This could lead to lower prices and thus lower returns for the VC investor, up to the prevention of transactions that otherwise would have taken place.

I analyze whether the forced forfeiture of LCFs impairs VC funding of start-ups by exploiting variation in the design of anti-tax loss trafficking rules within countries over time. Some of the EU28 Member States ${ }^{1}$ introduced new or relaxed existing restrictions over the last two decades. The regulations target abusive transactions, not VC funding of start-ups. It is unlikely that legislators change them in response to developments in the VC market. Therefore, I do not view reverse causality as a problem. First, I conduct several case studies. I match companies in countries where restrictions were introduced or altered to companies in similar countries without a change in legislation. Second, I employ a combined analysis of several types of changes. For this purpose, I utilize a ranking of the different anti-abuse systems based on their strictness, as described in Bührle and Spengel (2020). I perform both analyses with an event study and a difference-in-differences (DiD) design. I employ firm and year fixed effects in addition to timevarying country- and firm-level control variables.

I base the empirical analysis on the VICO 4.0 database, a firm-level dataset of EU28 companies that received VC funding between 1999 and 2014. VICO 4.0 is a combination of data on European start-ups from several proprietary datasets. Researchers compiled the database under the European Commission's "Research infrastructure for and innovation policy studies" (RISIS) project. So far, mainly finance and management researchers employed the data for research on the VC industry (e.g., Bertoni, Croce, \& Guerini, 2015; Croce, D’Adda, \& Ughetto, 2015; Croce, Martí, \& Murtinu, 2013; Grilli \& Murtinu, 2014; Guerini \& Quas, 2016).

My results indicate a significant and large negative effect of anti-tax loss trafficking restrictions on the VC funding volume provided to a company. Particularly my findings in Slovenia, where restrictive ownership-based regulations were introduced and later relaxed to a cumulative regime, illustrate the effect of anti-tax loss trafficking rules: Stricter rules exert a stronger and more significant negative influence. Less restrictive regulations do not seem to impair VC funding. The estimates of the combined analysis are in line with the results of the case studies. I find a more substantial and significant impact on older companies aged between ten and 15 years.

${ }^{1}$ EU28 refers to the European Union Member States at 2014, before the Brexit in 2020. 
Therefore, the tax regulations might be more relevant at later investment stages. In line with my expectations, companies in high-tech sectors seem to be predominantly affected: High-tech start-ups, on average, receive more VC funding and carry higher losses, rendering the impairment due to the restrictions more severe.

My research is related to several strands of literature. First, I add to the literature on the determinants of VC funding. In this context, evidence on the effect of taxes is rather scarce; researchers have considered taxation as one factor among many (Da Rin, Hellmann, \& Puri, 2013; Jeng \& Wells, 2000). Some studies specifically focus on corporate income (Da Rin, Di Giacomo, \& Sembenelli, 2011) or capital gains taxes (Edwards \& Todtenhaupt, 2020; Keuschnigg \& Bo Nielsen, 2003; Keuschnigg \& Nielsen, 2004). Da Rin, Nicodano, and Sembenelli (2006) consider temporal LCB and LCF provisions in the context of VC markets. Their results do not suggest that forfeiture of accumulated losses after a specified amount of time significantly decreases VC activity. While this could indicate that VC investors do not attach much importance to LCFs, this finding does not necessarily extend to the forfeiture of LCFs due to tax loss transfer restrictions. Second, and more specifically, I shed light on the impact of anti-tax loss trafficking rules. So far, the literature has focused on temporal loss restrictions for LCBs and LCFs. Empirical studies point towards adverse effects of temporal restrictions of tax loss assets: They increase effective tax rates (Cooper \& Knittel, 2010), impair corporate investment decisions (Bethmann, Jacob, \& Müller, 2018; Dreßler \& Overesch, 2013; Niemann, 2004), and discourage entrepreneurial risk-taking (Haufler et al., 2014; Langenmayr \& Lester, 2018; Ljungqvist, Zhang, \& Zuo, 2017; Mehrmann \& Sureth-Sloane, 2017). These impairments disproportionally hit small and newly established firms. Several authors discuss the reason for anti-loss trafficking rules (Bührle \& Spengel, 2020; Hoenig, 2014; Nijhawan, 2015; Poitevin, 2003). Moore and Pruitt (1987) find that the tightening of loss transfer restrictions in the US lead to a decrease in the market valuation of loss-reporting companies. Taken together, the empirical literature suggests that loss provisions matter, and more so for young compared to mature companies. There is a growing literature on LCB and LCF regulations, but evidence on anti-loss trafficking rules and their impact on VC funding is still missing.

Evidence on the effect of tax loss provisions on VC funding is relevant for policymakers. My results substantiate the ongoing debate about tax loss restrictions with empirical evidence. The findings support the notion that anti-tax loss rules (unintentionally) impair start-up financing. 
Therefore, it is advisable for policymakers to factor in potential adverse effects on the VC environment when designing anti-abuse legislation. ${ }^{2}$ As the European market is still lacking behind the American VC industry (Hege, Palomino, \& Schwienbacher, 2009), it is vital to remove possible obstacles. Impairment of VC investment might harm a country's competitive position (Carpenter \& Petersen, 2002a). The effect of tax loss restrictions gains in relevance in the context of the COVID-19 pandemic: Due to lockdowns, sales shortfalls, and generally unfavorable economic conditions, corporate losses are on the rise. Especially in times like these, supporting future-oriented companies could speed up the recovery of the economy.

The paper is structured as follows: In section 2, I provide a brief introduction to the VC funding process and tax loss restrictions. Based on this theoretical foundation, I develop my hypotheses. I present the description and sources of the data utilized in the third section. Section 4 contains a selection of case studies. In section 5, I conduct the combined analysis, complemented by several heterogeneity analyses and robustness checks. I conclude in section 6.

\section{Setting and Hypothesis Development}

In this section, I first describe the process of VC funding (section 2.1), continued by an overview of the tax treatment of losses (section 2.2). In the last sub-section, I connect both aspects and pose my hypotheses (section 2.3).

\subsection{The Stages of Venture Capital Financing}

Start-ups often suffer from credit constraints. At some point, the private savings of the founder are insufficient to cover the start-up expenses; the company depends on external financing. Start-ups have difficulties satisfying their capital demand with bank loans or other traditional funding opportunities since they lack adequate collateral (Carpenter \& Petersen, 2002b, 2002a; Cosh et al., 2009; Da Rin et al., 2006). VC investors target this type of firm and offer VC funding as a form of equity financing to young and risky companies. The investment is usually conducted long-term over several years, and includes additional advice and strategic support apart from the financing supplied. In the last quarter of 2019, VC-backed companies raised a total of $\$ 63.1$ billion worldwide, thereof $\$ 34.2$ billion in the US alone (54.2\% of worldwide VC raised). With $\$ 7.9$ billion (12.5\% of worldwide VC raised) in the fourth quarter, the volume attributed to European companies is substantially lower (KPMG, 2020). The overall trend shows an ongoing increase in VC funding over the last years. Nevertheless, the European VC

\footnotetext{
${ }^{2}$ Anecdotal evidence supports this concern, e.g. NVCA, https://nvca.org/pressreleases/nvca-cheers-prioritization-startup-loss-carryforward-rule-reforms/ (05.11.2020), FAZ, https://www.faz.net/aktuell/wirtschaft/unternehmen/wie-helmut-jeggle-ueber-die-biontech-aktie-denkt-17007068.html (19.10.2020).
} 
market still lacks behind compared to the environment start-ups face in the US (Hege et al., 2009). Particularly European countries should therefore be aware of any obstacles to VC.

VC investors participate in the up- as well as the downward risk of their protégés. Ideally, the investment yields a high return once the VC investors exit the company by selling their share in a trade sale or public offering. In the worst case, they lose the investment if the start-up fails. Therefore, evaluating potential investment opportunities weighs the associated risk against expected exit gains before the VC investors decide to get involved. The business plan, as well as the start-up founders and the management team, are assessed, followed by a thorough due diligence review (Macmillan, Siegel, \& Narasimha, 1985; Petty \& Gruber, 2011).

\section{Figure 1: Five stages of venture capital financing}

\section{Stage 1: Start-up stage}

- Newly formed company with limited track records, feasibility and market testing

- Potential investors: entrepreneur, friends and family

\section{Stage 2: Seed or early stage}

- Business concept, product development

- Potential investors: angel investors (wealthy individuals that know the founder pesonally) and early stage VC funds

\section{Stage 3: Growth stage}

- Working business model

- Potential investors: VC investors

\section{Stage 4: Late stage}

- Up-scaling of product, increase in market share

- Potential investors: VC investors

\section{Stage 5: Buyouts and recapitalizations}

- Profitable and stable company

- Potential investors: General public (exit of VC investors)

Source: Own depictions, based on Madison Park Group's "Guide to Venture Capital".

Five stages of start-up financing are commonly differentiated (Figure 1). Investors can provide VC financing at several of these stages. Over time, companies often conduct multiple funding rounds. Typically, the funding volume offered increases during the funding life cycle, as the start-up grows and can test the product idea in the market. VC investors will incorporate aspects of the current and subsequent stages into their decision-making process, taking into account 
expected exit gains in the last stage. Research has not yet clearly determined whether taxes play a role in this decision process.

\subsection{Loss Carryforwards and Anti-tax Loss Trafficking Rules}

In their first stages, start-ups accumulate losses during product development until they enter the market and can generate sufficient revenue to break even. For tax purposes, the majority of the European countries treat losses asymmetrically. ${ }^{3}$ Profits are subject to taxation, whereas losses do not immediately result in a tax refund. Instead, they have to be set off against positive income in previous (LCB) or following periods (LCF). These tax loss assets carry value (assuming the company becomes profitable or used to generate profits in the past) as they embody potential tax savings. Research indicates that LCFs affect stock prices when loss-carrying firms are acquired; evidence for a pricing-in by the participating firms is ambiguous (Chiang, Stammerjohan, \& Englebrecht, 2014; Haw, Pastena, \& Lilien, 1987; Hayn, 1989; Henning, Shaw, \& Stock, 2000; Plummer \& Robinson, 1990). However, LCFs are subject to temporal and relative restrictions. Studies show that these tax assets tend to be concentrated among young firms (Cooper \& Knittel, 2006). Compared to mature firms, newly established companies face on average higher losses and lower loss utilization rates as well as higher expected tax rates. As a result, new firms and certain industries, such as the information sector, are disproportionally disadvantaged by asymmetric tax loss treatment (Cooper \& Knittel, 2010). Similarly, Zwick (2021) shows that especially small companies eligible for loss offset do not claim their refund due to tax complexity. Overall, the temporal and relative loss limitations seem to hit start-ups in particular.

In addition to temporal restrictions, anti-tax loss trafficking rules can lead to the forfeiture of accumulated tax LCFs. Absent tax loss transfer limitations, unprofitable corporations with high LCFs can be acquired and merged with profitable firms to set off the otherwise worthless losses. The restrictions aim to prevent loss trafficking; in other words, the acquisition of shell companies with significant LCFs but without any economic activity. Legislators deem these transactions abusive as the sole purpose is the transfer of the tax assets. The restrictions apply to all corporations and do not target start-ups or VC-funded companies. However, the systems rely on general criteria to cover a broad spectrum of cases. Depending on the specific design, the limitations could also affect transactions with an economic justification, such as VC exits.

\footnotetext{
${ }^{3}$ Exceptions are Estonia (already for decades) and Latvia (since 2018). In their tax systems, corporate tax is levied upon distributions only, thus rendering tax loss restrictions irrelevant. Also outside the EU, asymmetric treatment of profits and losses is the general rule (e.g. in large economies such as the United States, Canada or China).
} 
In 2018, 21 of the EU28 Member States had anti-tax loss trafficking regulations, with various designs across countries (Bührle \& Spengel, 2020). ${ }^{4}$ The provisions commonly refer to a significant change in ownership and/ or a change in activity as triggering criteria. What constitutes such a significant change differs depending on the national legislation. In general, a change in ownership is considered harmful when the controlling majority of the corporation carrying the losses changes. The aim is to limit the benefits of LCFs to the shareholders that bore them. Changes in activity are often evaluated based on changes in assets, turnover, or targeted customer markets. The legislator ties the use of losses to profits generated by the activity that caused them in the first place. Several papers discuss the rationale behind anti-loss trafficking rules (Bührle \& Spengel, 2020; Hoenig, 2014; Nijhawan, 2015; Poitevin, 2003). Moore and Pruitt (1987) investigate the change in stock prices after the revision of anti-tax loss trafficking rules in the US in 1984. They find that the change in legislation lead to a reduction in the market value of loss-reporting companies, because the present value of their loss carryforwards declined. I am not aware of any study empirically investigating the effect of those restrictions in the context of VC funding.

\subsection{Venture Capital Investors and the Expected Value of Loss Carryforwards}

Legislators implement tax loss transfer restrictions as anti-abuse legislation. They aim to prevent tax-motivated acquisitions of shell companies with large LCFs but negligible economic activity. However, the regulations could distort the funding of young companies. ${ }^{5}$

As previously outlined, the empirical literature points towards adverse impacts of temporal and relative tax loss deduction limitations, which disproportionally hit small and newly established firms (Cooper \& Knittel, 2006, 2010; Zwick, 2021). Furthermore, disadvantageous loss provisions discriminate against risky investments (Haufler et al., 2014; Langenmayr \& Lester, 2018; Mehrmann \& Sureth-Sloane, 2017). However, when it comes to a venture capitalist's investment decision, it is unclear whether taxation generally plays a role. To the best of my knowledge, Da Rin et al. (2006) are the only authors that consider the impact of temporal tax loss restrictions on VC activity. They do not find significant effects. In contrast, I investigate anti-tax loss trafficking regulations, in other words the forfeiture of LCFs not after a specified amount of time but due to a specified event (changes in activity or ownership). Nevertheless, the irrelevance of temporal loss restrictions for $\mathrm{VC}$ activity could indicate that taxes and loss regulations might

\footnotetext{
${ }^{4}$ Bührle and Spengel (2020) provide a more detailed discussion of the design and development of the regulations. While my analysis focuses on Europe, tax loss transfer restrictions are applied throughout the world, such as e.g. the Section 382 limitation of the American IRC or Section 111 of the Canadian ITA.

${ }^{5}$ E.g. as mentioned by the National Venture Capital Association (NVCA): NVCA, https://nvca.org/pressreleases/nvca-cheers-prioritization-startup-loss-carryforward-rule-reforms/ (05.11.2020).
} 
simply not matter to VC investors. Particularly in connection with high-tech start-ups, they might concentrate on other aspects such as the nurture of novel ideas and technological progress. However, while the forfeiture of LCFs due to time restrictions might not be considered in a VC context, this finding is not necessarily transferable to the denial of LCFs due to tax loss transfer restrictions.

If taxes do matter, investors might be reluctant to fund a start-up's R\&D expenditure if accumulated LCFs are worthless due to tax loss restrictions (Haufler et al., 2014). Restrictive temporal and relative loss provisions aggravate the costs of bankruptcy as start-ups are, in contrast to diversified mature companies, unable to offset losses stemming from a failed project with profits from other projects (Henrekson \& Sanandaji, 2011). Also, firms can potentially lose built-up LCFs after significant changes in ownership after an IPO or an acquisition by another company (events which depict the usual divestment strategies of VC investors (Schwienbacher, 2008)). As a result, valuable LCFs are forfeited and thus not usable for succeeding investors. Sellers incorporate tax loss assets in their company valuation, as they still carry value before the divestment. At the same time, buyers exclude them, as they might be forfeited after the exit. This difference in valuation potentially leads to differences in asking and bidding price, decreasing prices, or preventing transactions altogether (Sureth-Sloane \& Vollert, 2009). Overall, anti-tax loss trafficking rules can destroy significant value, raising the risk associated with VC funding. The risk increase could lead VC investors to reduce their investment or even to refrain from funding a start-up at all.

However, anti-loss trafficking rules target so-deemed abusive tax-motivated acquisitions. Legislators already provide escape clauses to avoid punishing economically justified transactions. These exemptions can release companies that are in the process of financial rehabilitation, publicly quoted, part of a group, or carry hidden reserves. Some countries allow corporations to provide evidence of economic reasons for the transaction to refute the abuse assumption. Depending on the effectiveness of these escape clauses, loss provisions might not impact lossmaking start-ups the way they are supposed to affect bankrupt companies. Nevertheless, for start-ups, often only the provision of evidence is viable, if available.

Overall, it is unclear whether anti-tax loss trafficking regulations impair VC funding. First, it is in dispute whether taxes matter at all for VC investment decisions. In response to the restrictions, investors could reduce their contribution. Given that they do, exemptions for start-ups might mitigate the impairment. I pose the following hypothesis:

H1: Anti-tax loss trafficking rules negatively affect the VC funding volume of a company. 
The impact will likely differ depending on the specific regulation (Bührle \& Spengel, 2020). Stricter rules will make it more likely that a company is affected by a change in its structure, whereas a more lenient regime will impose lower risks. Taking the exit strategy of investors into consideration, anti-tax loss trafficking rules relying on a change in ownership as triggering criteria pose the biggest threat. If venture capitalists buy substantial shares in a company and divest later, accumulated LCFs could be forfeited. Activity-based rules can, albeit less restrictive, still have potentially adverse effects if the start-up's business strategy is changed to accommodate altered conditions or to market the product better, and if these changes are deemed harmful by the tax authorities. Lastly, cumulative requirements, which require a change in activity in addition to a change in ownership with a close temporal connection, pose the least distortionary restriction. If either one of the criteria is not fulfilled, in other words, if corporations are subject to either only a change in ownership or only a change in activity, LCFs are not affected. Based on this argumentation, I add the following hypothesis:

H2: The impairment in VC funding due to anti-tax loss trafficking rules depends on the specific type of change. Ownership-based regimes are more restrictive than activity-based regimes, and activity-based regimes are more restrictive than cumulative regimes.

\section{3. $\quad$ VC Funding in the EU28}

I conduct the empirical analysis of the hypotheses set up in the preceding section with data of VC-backed European start-ups taken from the VICO 4.0-database. Multiple researchers have compiled the database as part of the European Commission's "Research Infrastructure for Science and Innovation Policy Studies" initiative. It contains information on European companies that received at least one round of VC financing from 1998 to 2015. The database is a combination of different proprietary databases that have been matched to provide a more comprehensive sample of VC-backed companies in the EU28. Additionally, financial statement information has been obtained from BvD's Orbis database. To the best of my knowledge, VICO 4.0 is unique in its coverage and combination of data on the VC activity and features of European companies. ${ }^{6}$ The data has been used in several studies in other research areas (e.g., Bertoni, Croce, \& Guerini, 2015; Croce, D’Adda, \& Ughetto, 2015; Croce, Martí, \& Murtinu, 2013; Grilli \& Murtinu, 2014; Guerini \& Quas, 2016).

\footnotetext{
${ }^{6}$ For detailed information on the VICO 4.0 database, the construction of the final sample, and a discussion of potential sample selection bias, please refer to the appendix A2. The section also provides information on the geographical and temporal distribution of the observations.
} 
For the empirical analyses conducted in this study, I remove 2015 from my sample because a large drop in observations indicates incomplete data in the last year. The initial sample consists of 140,534 observations of 11,665 distinct companies, of which 14,650 company-year observations report non-zero values of VC funding. Figure 2 depicts the mean and median per firm (left y-axis) and sum across all firms (right y-axis) of VC funding received by companies in the sample. An apparent spike in 2000 and a subsequent drop in 2001 marks the burst of the Dotcom-bubble in that period. The financial crisis also resulted in a decline after 2008. While the overall sum of VC funding in the last decade is far from pre-Dotcom-levels, it started to increase again. Across all periods, the median lies below the mean, indicating that the data is skewed to the left. Several companies that received large sums of VC funding lead to a comparatively high mean, while more than half of the companies that raised funding received considerably lower amounts.

\section{Figure 2: Development of VC funding in the EU28}

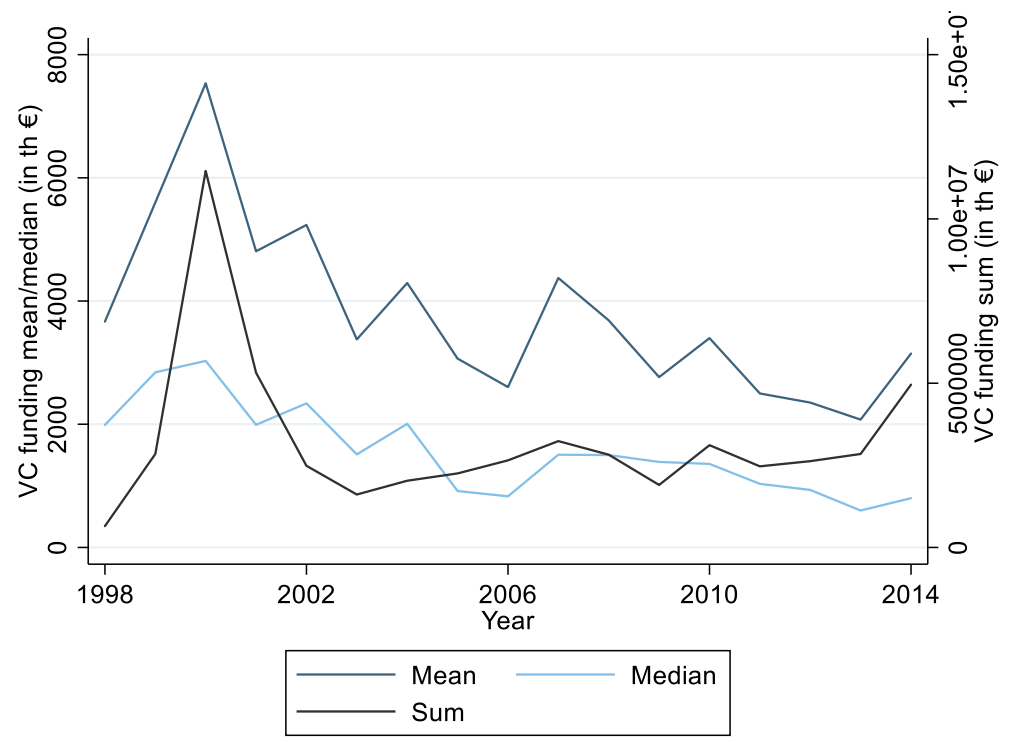

Notes: Left y-axis: VC funding mean and median per firm in the sample. Right y-axis: VC funding sum across all firms in the sample. Winsorized at 1\% and $99 \%$ level, excluding observations with zero VC funding. Coverage: 1998 to 2014, EU28 Member States. Source: Own depiction based on VICO 4.0.

4. Country Case Studies

I first focus on individual changes. In the following sub-sections, I explore the anti-tax loss trafficking regulations in three selected countries: The introduction of an ownership-based and subsequent switch to a cumulative regime in Slovenia (4.2), the introduction of a cumulative regulation in the Czech Republic (4.3), and the change from a cumulative to an ownershipbased restriction in Germany (4.4). Compared to other European anti-tax loss trafficking rules, these three regimes were particularly restrictive. Both Slovenia and Germany implemented 
ownership-based regimes. The Czech Republic employed more lenient cumulative restrictions. However, the low threshold for the application of the rules increased the risk of loss forfeiture compared to other regimes that only applied after larger changes in ownership. From the changes in legislation observed in my sample period, these three cases entailed the largest risk increase for investors. The appendix A4 entails additional case studies for less restrictive regimes. ${ }^{7}$

\subsection{Identification Strategy}

In each case study, I estimate the effect of the specific change in legislation based on a DiD design. I compare how much VC funding affected companies receive after compared to before the treatment. To rule out confounding events affecting VC investment, I construct a comparable control group that was not subject to a change in legislation. The common trend assumption requires treatment and control groups to behave similarly before the change in anti-tax loss trafficking regulations.

Within a country, all companies are subject to anti-tax loss trafficking rules and, therefore, considered treated. Consequently, the control group has to consist of companies from other countries. To construct a comparable sample, I restrict the selection of countries that I consider: First, I exclude countries with changes in legislation within a four-year window before and after the event in the treatment country. Second, I limit the choice set to control countries similar to the treatment country in GDP and CIT level. In the next step, I match treated companies with non-treated companies chosen from the constrained control country set. I match on the age and total amount of assets of a company in the three years preceding the treatment. ${ }^{8}$ As a matching approach, I employ coarsened exact matching (CEM). With CEM, similar values of the matching parameters are grouped; in other words, coarsened. Each group is then assigned a numerical value. Treated and control companies are exactly matched based on these parameter groups instead of the individual parameter value (Iacus, King, \& Porro, 2011, 2012). ${ }^{9}$ I match with replacement and exclude companies without a match.

For each case study, I employ an event study and a DiD approach for the matched sample. The event study results depict estimates at different points in time and establishes the common trend

\footnotetext{
${ }^{7}$ The additional case studies are provided for sake of completeness. Including all case studies in the main part of the paper would increase the length excessively.

${ }^{8}$ I match on pre-treatment covariates instead of outcome variables, as the latter could increase bias (Chabé-Ferret, 2017). In my regressions, the coefficients for age and firm size are a statistically significant predictor of VC funding volume.

${ }^{9} \mathrm{CEM}$ also defines missing values as a group. In my setting, this poses an advantage compared to e.g. propensity score matching, which requires full information on all chosen matching parameters. In my sample, accounting information is unavailable for around $74 \%$ of the company-year observations. Requiring non-missing values for assets over a period of three years would pose a binding restriction and introduce severe sample selection bias.
} 
assumption. The $\mathrm{DiD}$ analysis estimates the overall effect across all years following the change in legislation.

I set the main focus on anti-tax loss trafficking rules as explanatory variables. I take information on tax loss provisions in the EU28 Member States from Bührle and Spengel (2020). ${ }^{10}$ As elaborated on above, tax loss transfer restrictions rely on one or a combination of two different criteria: Changes in ownership and changes in the activity of the company. I provided more detailed information on the country-specific design in the respective country case studies.

Anti-tax loss trafficking rules are generally aimed at so-deemed abusive transactions and do not target VC divestments. Legislators usually implement changes out of tax avoidance concerns in the context of mergers of long-established corporations or in response to court decisions. Therefore, I do not expect reverse causality to pose a threat in my setting.

First, I follow the standard event study design as explained in Schmidheiny and Siegloch (2019). The regression equation for the event study reads as follows:

$$
\begin{aligned}
& \log \left(\text { VC funding } \text { fun, }_{f, t}\right) \\
& \qquad \alpha_{0}+\beta * \text { Event }_{c, t}+\sum_{t-4}^{t-1} \gamma_{n} \text { Lead }_{n}+\sum_{t+1}^{t+4} \gamma_{m} \text { Lag }_{m}+\delta C+F E_{f} \\
& +F E_{t}+\varepsilon_{f, c, t}
\end{aligned}
$$

The treatment dummy Event $t_{c, t}^{j}$ equals one at the time of change in legislation in the treatment country and zero otherwise. I include four leads and four lags, respectively. I bin treatment indicators at the ends of the event window in $\mathrm{t}-4$ and $\mathrm{t}+4 .{ }^{11}$ I follow the standard and standardize the coefficient in the period preceding the treatment, $\gamma_{n=t-1}$, to zero. As a result, the other coefficients are expressed as changes in VC funding compared to the basis in $\mathrm{t}-1$.

Second, I estimate the overall effect in a DiD analysis:

$$
\begin{aligned}
& \log \left(V C \text { funding }_{f, c, t}\right) \\
& \qquad=\alpha_{0}+\beta * \text { Treatment }_{c} x \text { Reform }_{t}+\delta C+F E_{f}+F E_{t}+\varepsilon_{f, c, t}
\end{aligned}
$$

Treatment $_{c}$ is a dummy equal to one for the treated country and zero otherwise. Reform f $_{t}$ equals one for the year of the change in legislation and subsequent years, and zero otherwise.

\footnotetext{
${ }^{10}$ Bührle and Spengel (2020) compile their data from the IBFD Country Analyses and a number of tax guides (PwC, EY, KPMG). Additionally, assisted by a translation program, they verify and supplement the collected information with references to national tax law.

${ }^{11}$ Binning the endpoints accounts for the limited effect window. It assumes that the effect stays constant before and after the period explicitly modeled. Thus, the estimate for $\mathrm{t}=4 \mathrm{can}$ be interpreted as a long-term effect.
} 
The coefficient $\beta$ for the interaction of both dummies represents the effect of the change in legislation on VC funding for the treated companies.

I employ the same dependent and the same set of control variables in both the event study and the DiD analysis. For the dependent variable, the logarithm of the VC funding volume $V C$ funding $g_{f, c, t},{ }^{12}$ I consider the $\mathrm{VC}$ funding that a company $f$ in country $c$ received in year $t$. I derive the variable by summing up the equity raised by the company stemming from all funding rounds within one year.

In some countries, escape clauses allow for exemptions from the restriction in some instances. I account for these clauses with a dummy variable. If legislators exempt firms from tax loss transfer restrictions based on rehabilitation, quoted companies, group affiliation, hidden reserves, or evidence of economic justification, I set Escape clause to 1. As most of the exemptions are not viable for start-ups, I only expect a small positive effect, if any.

In addition to the main independent variables of interest, I employ different country-level controls, pooled in the vector $C$. I include the statutory corporate tax rate $(C I T)^{13}$ as well as the change in tax rates compared to the previous year $(\Delta C I T)$. Higher tax rates decrease the aftertax return for corporate VC investors. Also, the value of LCFs is contingent on the applicable tax rate at the time of the loss offset. ${ }^{14}$ On the one hand, deducting LCFs in a high-tax country yields higher tax savings than offsetting an equal amount of LCFs in a low-tax country. On the other hand, a higher value of LCFs entails a greater loss in value if firms cannot use these tax assets. Furthermore, studies indicate that capital gains taxes at the investor level also influence VC investment (Edwards \& Todtenhaupt, 2020). Thus, I include statutory capital gains (CGT) and dividend tax rates $(D T)$. To account for temporal loss restrictions, all specifications include the number of years for which losses can be carried back (zero if not available) and forward. ${ }^{15}$ I consider relative loss restrictions, in other words, size limitations, with LCF limit. The dummy is set to 1 if relative restrictions apply and zero otherwise.

I rely on variables generally employed in the literature and control for a country's economic environment by utilizing its GDP per capita and growth (Bernoth \& Colavecchio, 2014; Cherif \& Gazdar, 2011; Félix, Pires, \& Gulamhussen, 2013; Li \& Zahra, 2012). The set of controls

\footnotetext{
${ }^{12}$ E.g. Edwards and Todtenhaupt (2020) also employ the natural logarithm for their dependent variable, the amount of equity raised by a start-up.

${ }^{13}$ LCFs are deducted from the company's taxable income. Tax base effects such as e.g. depreciation, are not relevant in this case. Therefore, I do not use effective tax rates which include these effects.

14 The relevant tax rate to be considered is the tax rate of the residence country of the company that incurred the losses. For non-group companies, cross-border loss offset is generally not allowed based on current tax law.

${ }^{15}$ In case of an unlimited carryforward, following Langenmayr and Lester (2018), I set the variable to 20.
} 
also encompasses inflation, measured by changes in the consumer price index (Bernoth \& Colavecchio, 2014; Langenmayr \& Lester, 2018). To account for the local labor market, I utilize the unemployment rate (Bernoth \& Colavecchio, 2014; Cherif \& Gazdar, 2011; Félix et al., 2013; Lüken, 2014).

Government-funded investments influence the VC environment. Public VC investment should (in contrast to private $\mathrm{VC}$ investment) not react to local tax regulations. An increase in public funding increases the overall VC funding volume available in a country. One of the major players in the European VC market is the European Investment Fund (EIF). By working with local VC funds as intermediaries, they distribute equity financing and guarantees provided by institutions such as the European Commission or regional authorities. I include the amount of support (EIF amount) and the number of supported companies (EIF number) per country per year. I additionally account for public investment with the lagged amount of government-funded PE investment (Lagged Public PE). Table 11 in the appendix gives an overview of all variables and their sources.

Finally, I include firm- and year fixed effects. Instead of employing time-varying firm-level controls in the case studies, I rely on matching as elaborated on above. Firm-level accounting information is available for less than a fourth of the observations; additional firm-level controls would therefore greatly limit the sample size. ${ }^{16}$

\subsection{Slovenia}

Slovenia first introduced an ownership-based loss transfer restriction in 2005, denying the offset of loss carryforwards after a change in ownership above $25 \%$. In 2007 , the threshold was increased to $50 \%$, and an activity clause was added. Furthermore, an exemption was included for rehabilitation measures.

Figure 3 illustrates the effect of the legislation changes, where the first event at $t=0$ depicts the first change in 2005 and the second event at $t=2$ represents the second change in 2007. ${ }^{17}$ There are no apparent differences between treated and control companies before the introduction of the ownership-based regime. The results indicate that VC funding dropped significantly in response to the restrictions. Two years later, when the regulation was relaxed by introducing the cumulative requirement, the coefficient estimate turns positive. This change in VC funding

\footnotetext{
${ }^{16}$ Depending on the national regulations, SMEs are not required to publish financial statements up to a certain size threshold, or do so in a shortened version. More than half of the companies report losses which presumably result in LCFs.

${ }^{17}$ In deviation from the regression equation stated in formula (1) and (2), in the case of Slovenia governmentfunded PE is not included as a control. The data provided by InvestEurope does not include Slovenia until 2007. However, the controls for funding programs from the EIF are available.
} 
aligns with both my hypotheses: VC funding decreased in response to the introduction of restrictions. When the anti-tax loss trafficking rules were relaxed, the impairment vanished. Unsurprisingly, the overall effect is not statistically different from zero.

\section{Figure 3: Results case study, Slovenia}

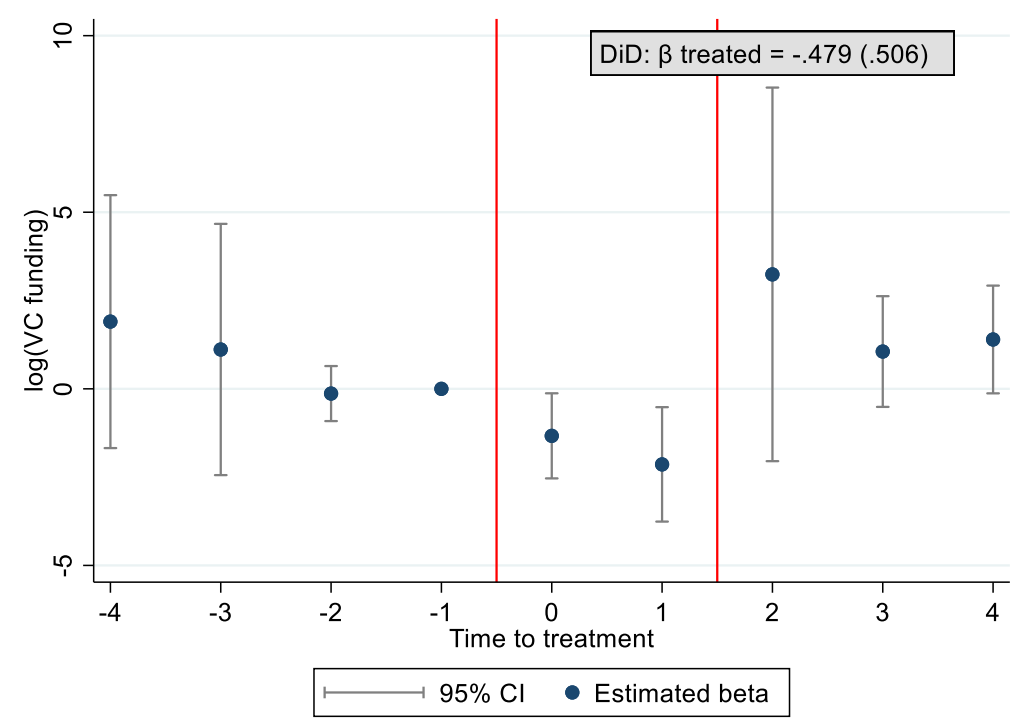

Notes: Events: Slovenia, introduction ownership-based regime in 2005 and change to cumulative regime in 2007. Dependent variable: Firm-level VC funding volume. Main graph: Results of the event study, difference between treatment and control group. Time dummies: "0": time of change in legislation. "-t": leads. " $t$ ": lags. 95\% confidence intervals. Grey box: Results of the panel analysis; standard error in parenthesis. *, **, and *** indicate significance at the 10,5 , and $1 \%$ level. Sample composition, descriptive statistics, event study results, and panel regression results: Table 13 to Table 16 (appendix).

\subsection{Czech Republic}

In 2004, the Czech legislators newly introduced tax loss transfer restrictions after substantial ownership and activity changes. The change in ownership was deemed substantial if one or a group of related persons gained more than $25 \%$ of a company's shares (e.g., due to acquisition or capital increase of existing shareholders). In such a case, the company could offset existing loss carryforwards only against future profits generated by business activities similar to those that lead to the losses. ${ }^{18}$ The law did not provide any explicit exemptions from the restriction.

Figure 4 depicts the results of the event study. There are no significant differences between the treatment and control groups preceding the change in legislation. After introducing the cumulative regime, Czech companies seem to receive less VC funding than their counterfactual peers in other countries. The effect is statistically significant in most of the periods post-treatment. The difference-in-difference analysis in the panel also results in a negative, albeit insignificant effect of the tax loss transfer restriction. Overall, the results suggest that the cumulative regime's

\footnotetext{
${ }^{18} \mathrm{An}$ income structure test required that at least $80 \%$ of the income was generated from the same activities.
} 
introduction negatively affected VC funding. The effect remains negative and statistically significant at the $10 \%$ level from the fourth year after the change onwards.

\section{Figure 4: Results case study, Czech Republic}

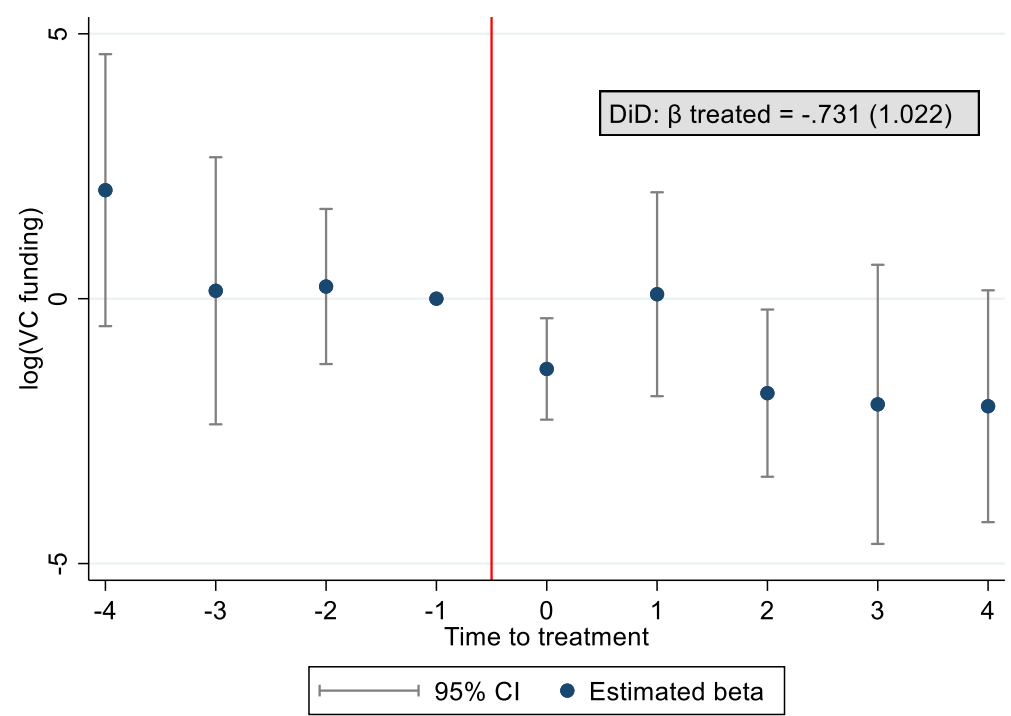

Notes: Event: Czech Republic, introduction cumulative regime in 2004. Dependent variable: Firm-level VC funding volume. Main graph: Results of the event study, difference between treatment and control group. Time dummies: "0": time of change in legislation. "-t": leads. "t": lags. 95\% confidence intervals. Grey box: Results of the panel analysis; standard error in parenthesis. *,**, and *** indicate significance at the 10,5 , and $1 \%$ level. Sample composition, descriptive statistics, event study results, and panel regression results: Table 13 to Table 16 (appendix).

\section{$4.4 \quad$ Germany}

The German tax law already restricted loss carryforwards after a cumulative change in ownership and activity since introducing the anti-abuse legislation in 1991. In 2008, the rules changed substantially. Previously, loss carryforwards were denied after a change in ownership exceeding $50 \%$ and discontinuing the original business. ${ }^{19}$ The German legislator cut the activity clause, resulting in a full extinction of loss carryforwards after a change in ownership above $50 \%$. Furthermore, a pro-rata denial was introduced for changes between $25 \%$ and $50 \%$. The regulations applied equally to an individual or a group of buyers and newly acquired shares or increases in existing shareholders' capital. Compared to other anti-tax loss trafficking rules present in the EU, the German scheme was particularly restrictive. ${ }^{20}$ Exemptions for rehabilitation, hidden reserves and corporate groups were not introduced until later years.

\footnotetext{
${ }^{19}$ This was also the case if the business was continued with predominantly new business assets. A rehabilitation clause applied if the company was active for at least 5 years after the change in ownership.

${ }^{20}$ The rules were criticized as "loss destruction provision". After ongoing criticism, an activity clause was added in 2016. In 2017, a court ruling even deemed the pro-rate forfeiture unconstitutional.
} 
The event study shows a clear negative trend in VC funding after changing the legislation (Figure 5). German companies received substantially lower VC funding volumes after implementing the ownership-based regime. The effect is statistically significant at the 5\%-level two years after the change in legislation and in the long run from the fourth year onwards. The differences between treated and control companies are statistically insignificant before the event, providing reassurance that both groups are comparable and behave similarly. However, the estimate is overstated (understated) if the control group companies were less (more) severely affected by the financial crisis that also hit in 2008. Considering that German companies emerged stronger from the crisis as compared to firms in other European countries, a bias of the results towards zero is more likely. Taken at face value, the panel estimate suggests an average decrease in VC funding of around $-40 \%$.

\section{Figure 5: Results case study, Germany}

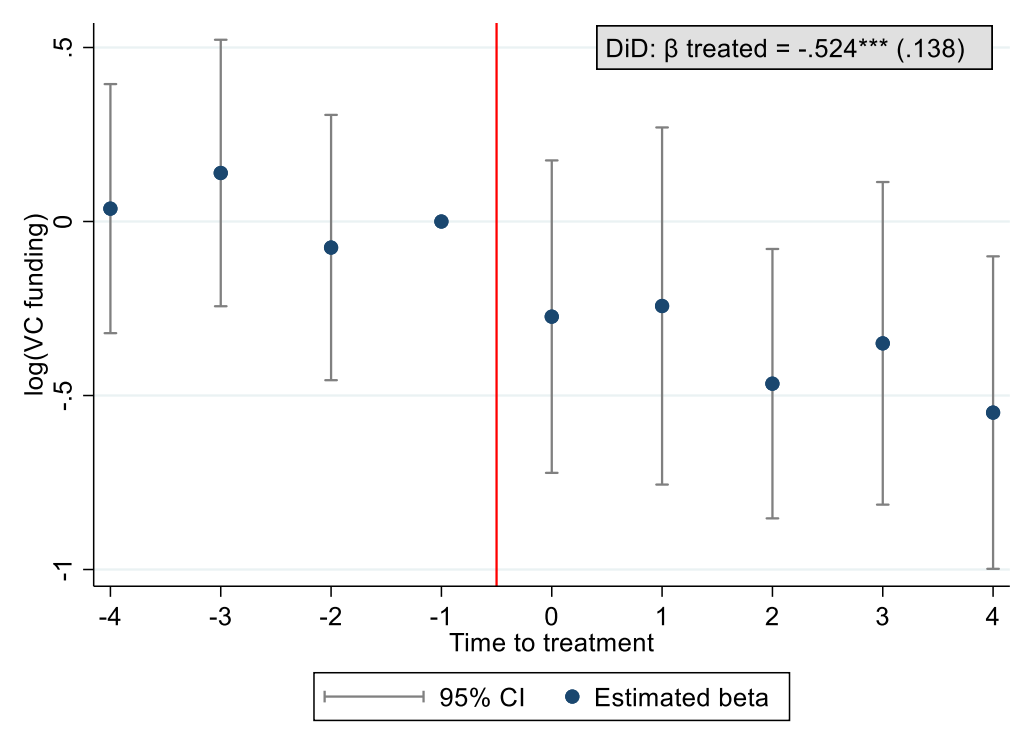

Notes: Event: Germany, change from cumulative to ownership-based regime in 2008. Dependent variable: Firmlevel VC funding volume. Main graph: Results of the event study, difference between treatment and control group. Time dummies: "0": time of change in legislation. "- $t$ ": leads. " $t$ ": lags. 95\% confidence intervals. Grey box: Results of the panel analysis; standard error in parenthesis. *,**, and *** indicate significance at the 10, 5, and $1 \%$ level. Sample composition, descriptive statistics, event study results, and panel regression results: Table 13 to Table 16 (appendix).

\subsection{Interim Findings}

The case studies presented in the previous sub-section and appendix A4 provide initial evidence for my first hypothesis: Strict anti-tax loss trafficking rules seem to impair VC funding.

In line with my second hypothesis, the severity of the impairment differs depending on the regime type. The ownership-based regimes in Germany and Slovenia are more restrictive than other regulations in place in the EU. First, the limitation to the ownership criterion leads to the 
forfeiture of loss carryforwards, even if the company itself and its business do not change. Second, the thresholds applied were relatively low. The minimum trigger of $25 \%$ is far below the commonly defined threshold of a change of controlling interest of 50\%. In that sense, the Czech regime is also comparatively restrictive, albeit it provided an additional activity clause. The results reflect these constraints. While VC funding decreased after the change in legislation in all three cases, I can only establish a long-run effect for the German regime. For the introduction of less restrictive cumulative regulations, such as in Lithuania in 2002 and Hungary in 2012 (see appendix A4), I do not find any significant effect.

\section{5. $\quad$ Combined Analysis}

This section entails the combined analysis, where I consider changes in different countries simultaneously to derive more general results. For this purpose, I construct a categorical variable for the different types of anti-tax loss trafficking rules (section 5.1). Instead of matching the observations, I extend the empirical specification with firm-level control variables. This approach leads to a substantial decrease in sample size (section 5.2). I supplement the panel analysis (section 5.3) by heterogeneity analyses (section 5.4) and robustness checks (section 5.5)

\subsection{Categorization of Tax Loss Transfer Limitations}

So far, I have investigated individual events on a case-by-case basis. To conduct a combined analysis of all legislation changes in my sample, I divide the tax loss transfer restrictions into five categories based on their strictness (Table 1).

\section{Table 1: Categories of anti-loss trafficking rules}

\begin{tabular}{ll}
\hline Category & Description \\
\hline Category 0 & No explicit anti-loss trafficking rule \\
Category 1 & $\begin{array}{l}\text { Denial of loss transfer after a change in ownership and activ- } \\
\text { ity (cumulative requirement) }\end{array}$ \\
Category 2 & Denial of loss transfer after a change in activity \\
Category 3 & Denial of loss transfer after a change in ownership \\
Category 4 & Denial of loss transfer after a change in ownership or activity \\
& (fulfillment of one criteria sufficient)
\end{tabular}

Notes: Categories of anti-tax loss trafficking restrictions, ranked based on their strictness. Source: Bührle and Spengel (2020).

For specific regulations (Categories 1 to 4), abuse is blanketly assumed based on codified criteria. The burden of proof of the opposite rests upon the taxpayer. In those cases, the cumulative requirement of a change in activity and ownership is the least restrictive measure (Category 1 ). 
As a firm has to fulfill both criteria, the forfeiture of LCFs can be avoided if the start-up maintains (and adequately documents) its business activity for the required periods, even if a new investor enters or existing investors increase their stake in the enterprise. If there is either only a change in ownership or only a change in activity, this type of restriction is not triggered.

The forfeiture of losses after a change in activity imposes a more severe restriction on start-ups (Category 2). Especially in the initial stages, when the business plan is developed, or at later stages, when an existing business strategy is adjusted, substantial changes might lead to a shift of the company's focus. However, given no changes in activity, new VC investors can participate and provide funding without triggering the anti-abuse regulation.

Anti-abuse regulations that solely rely on a change in ownership fall in a more restrictive category (Category 3). Within this category, any substantial VC divestment could pose a threat to accumulated LCFs within a start-up.

Category 4 finally includes countries that relate to either a change in ownership or a change in activity, where the fulfillment of either criterion is sufficient. This poses the most restrictive rule, as it includes all cases that would be covered by either Category 2 or $3 .^{21}$

\section{Figure 6: Comparison of loss transfer categories in the EU28, 2000 to 2014}

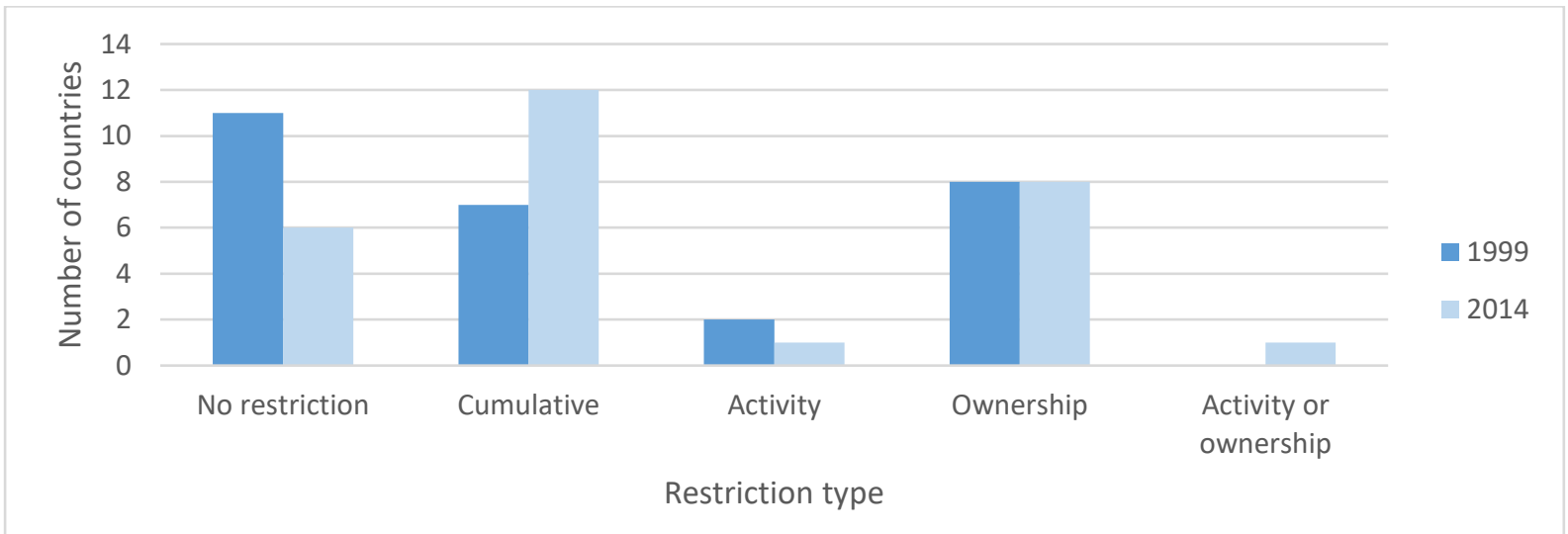

Notes: Number of countries applying anti-tax loss trafficking rules in a given year. Categories as defined in Table 1. Source: Table 12 in the appendix and Bührle and Spengel (2020).

Figure 6 compares the number of anti-tax loss trafficking rules in the EU28, differentiated by restriction category, from the first to the last year in the sample, 1999 to 2014 . The categories vary across countries and time. The empirical strategy implemented in the following sections exploits the temporal variation. Over the years, more restrictive legislation was implemented.

\footnotetext{
${ }^{21} \mathrm{~A}$ more detailed overview and description of the anti-tax loss transfer regulations is provided in Bührle and Spengel (2020). For the purpose of the following analyses, retro-actively applicable rules are disregarded. At the time of funding, the information on the change in legislation was not yet available and could therefore not have affected the investment decision. As a result, the coding of transfer restriction categories displayed in the appendix A1 (Table 12) slightly differs from the overview provided in Bührle and Spengel (2020).
} 
Throughout the sample period, I identify a total of eleven changes in legislation. The cumulative regimes' overall number has not changed as two countries tightened their restrictions (Germany and Greece) while two countries relaxed their rules (Hungary and the Netherlands). However, data restrictions only allow me to analyze five of these changes in the following, namely in the Czech Republic (2004), Germany (2008), Croatia (2010), Hungary (2012), and Greece (2014).

\subsection{Descriptive Statistics and Identification Strategy}

I cannot employ the matching approach previously utilized in a panel setting with treatments at different times in different countries. The matched case studies sample each consist of selected companies that are weighted to achieve the greatest degree of comparability between the casespecific treatment and control group. Neither combining the weighted observations from the individual case studies nor employing CEM on the full panel is viable to construct a regression sample. First, several of the companies in unaffected countries serve as a control for more than one change in legislation, possibly with a different weight. ${ }^{22}$ Second, companies that are affected at one point in time might serve as control companies in other periods. ${ }^{23}$ Therefore, I homogenize the sample by including the set of treatment and control companies that have been matched in the case studies, but without employing a weighting. Instead, I include several firmlevel controls to account for time-varying firm characteristics.

Analogously to the case studies, I use two approaches: An event study design and a DiD analysis. Firstly, I conduct a generalized event study following Schmidheiny and Siegloch (2019). This approach allows the analysis of multiple and repeated events of different treatment intensities. I note the regression equation as follows:

$$
\begin{aligned}
& \log \left(V C \text { funding }_{f, c, t}\right) \\
& \qquad \alpha_{0}+\sum_{j}^{J} \beta_{j} * \text { Treatment }_{c, t}^{j}+\sum_{t-4}^{t-1} \gamma_{n} \text { Lead }_{n}+\sum_{t+1}^{t+4} \gamma_{m} \text { Lag }_{m} \\
& +\gamma C+\delta F+F E_{f}+F E_{t}+\varepsilon_{f, c, t}
\end{aligned}
$$

In this specification, the treatment intensity Treatment $_{c, t}^{j}$ is the primary variable of interest. I define the treatment as a change in the restriction category in a country in a year. I derive the treatment intensity by calculating the number of categories the restriction scheme dropped (if

\footnotetext{
${ }^{22}$ Each company needs to be appointed a fixed weighting parameter. If one were to simply use the weighting matrices constructed in the individual case studies and combine them, a control company could have multiple weighting parameters, originating e.g. because it was matched to Hungarian as well as to Czech companies.

${ }^{23}$ I am not aware of any matching approach that would allow for the simultaneous matching of companies in the given setting.
} 
regulations were relaxed) or climbed (if rules were tightened). ${ }^{24}$ I include the treatment at the event time and with four leads and lags, respectively. I bin treatment intensity at the ends of the event window in $\mathrm{t}-4$ and $\mathrm{t}+4 .{ }^{25} \mathrm{I}$ again standardize the coefficient in the period preceding the treatment, $\beta_{t-1}$, to zero. Consequently, the remaining coefficients have to be interpreted as changes in VC funding compared to the basis in $\mathrm{t}-1$.

The estimates of the event study confirm that treatment and control groups displayed common trends before treatment and yield average treatment effects at specific points in time. It is possible to pinpoint the impact of tax loss restrictions at the year of implementation or investigate potential anticipatory effects before the legislation changes. Second, to calculate average treatment effects across the whole time horizon, I employ a generalized DiD approach:

$$
\begin{aligned}
& \log \left(V C \text { funding } \text { f }_{f, c, t}\right) \\
& \quad=\alpha+\beta \text { Restriction category }{ }_{c, t}+\gamma C+\delta F+F E_{f}+F E_{t} \\
& \quad+\varepsilon_{f, c, t}
\end{aligned}
$$

The categorical variable Restriction category ranges from zero to four, representing the different categories of anti-loss trafficking restrictions. Zero represents the least and four the most restrictive rule (as discussed in section 5.1). ${ }^{26} \mathrm{With}$ this approach, I include the full set of countries and regulations.

I employ the same dependent variable, country-level controls and fixed effects as in the case studies (4.1). In addition, the vector $F$ entails firm-level controls. It consists of the firm's assets with a one-year lag to control for firm size as well as LCFs based on the amount of profit and losses before taxes reported in the preceding year. The LCFs account for the expected economic damage if transfer restrictions apply; the higher the losses accumulated in a company, the higher the value of future tax savings that are denied. I also control for the company's age. These constraints induce a sample selection bias. The restriction to full information on the firm-level controls employed excludes micro and young companies. Consequently, the results have to be evaluated in light of this limitation.

Table 2 summarizes the descriptive statistics for the dependent variable, VC funding, and the firm-level control variables, assets, LCFs, and age, which I employ in the following empirical

\footnotetext{
${ }^{24} \mathrm{E}$.g. the introduction of a cumulative regime represents a move from Category 0 to 1 , thus leading to a treatment of +1 . The change from an ownership-based restriction to a cumulative scheme poses a move from Category 3 to Category 1 , resulting in a treatment of -2 .

${ }^{25}$ Binning the endpoints accounts for the limited effect window. It assumes that the effect stays constant before and after the period explicitly modeled.

${ }^{26}$ For more information, please refer to section 5.1 (Table 1), the appendix A1 (Table 12) and Bührle and Spengel (2020).
} 
analysis. The sample consists of many zeros for VC funding, as companies do not receive funding between different funding rounds. As a result, the median amounts to zero, while the mean is positive. Assets are highly skewed to the left and LCFs to the right, both towards zero. The age variable is also left-skewed, but less so than assets. As expected, VC-backed companies are rather young: More than half of the companies are aged below ten years.

Table 2: Descriptive statistics

\begin{tabular}{lcccccc}
\hline Variable & Obs & Std. Dev. & Min & Mean & Median & Max \\
\hline VC funding & 17,331 & $2,096.02$ & 0.00 & 349.12 & 0.00 & $120,946.05$ \\
\hline Total Assets & 17,331 & $13,940.60$ & 0.00 & 421.08 & 3.37 & $1,206,064.00$ \\
LCF amount $(1 \mathrm{yr})$ & 17,331 & 377.18 & $-19,660.24$ & -15.24 & 0.00 & 0.00 \\
Age & 17,331 & 7.69 & 0.00 & 10.07 & 9.00 & 165.00 \\
\hline
\end{tabular}

Notes: Summary statistics for the variables, as defined in Table 11 (appendix).

In the following tables, column (1) refers to the baseline specification with Treatment or Restriction category as explanatory variables, accompanied by firm fixed effects. Additionally, (2) includes year fixed effects. (3) adds country-level controls. (4) is the preferred specification and consists of the full set of control variables and fixed effects. ${ }^{27}$ All variables are defined as described before and as summarized in Table 11 in the appendix. Due to the use of one-year lagged control variables, I conduct the analyses from 1999 onwards.

\subsection{Main Analysis: Event Study and Generalized Difference-in-Differences}

Figure 7 (estimations based on equation (3)) depicts the estimates at the event time and before and after the legislation change. The $\mathrm{x}$-axis represents the time to treatment, the $\mathrm{y}$-axis the effect on the VC funding volume, standardized to the year preceding the change. A treatment intensity of one unit relates to the move from a restriction category to one higher category.

The event study yields clear evidence for an impairment of VC funding caused by anti-tax loss trafficking restrictions. Statistically, the difference between treatment and control companies is not different from zero before the treatments. After a change in legislation, all estimates are negative and statistically significant. The graph shows post-event negative estimates ranging around -0.5 , translating into an average reduction of $-39.3 \%$. Similarly, the overall treatment effect estimated in the panel regression is negative and statistically significant. The coefficient is slightly lower in magnitude, amounting to -0.44 , in other words, a reduction of around $-35.5 \%$ (Table 3, estimations based on equation (4)).

\footnotetext{
${ }^{27}$ Due to multicollinearity, I do not include country-year fixed effects. The changes in legislation considered here occur at the country level. Country-year fixed effects would be a perfect linear combination of the treatment variables.
} 


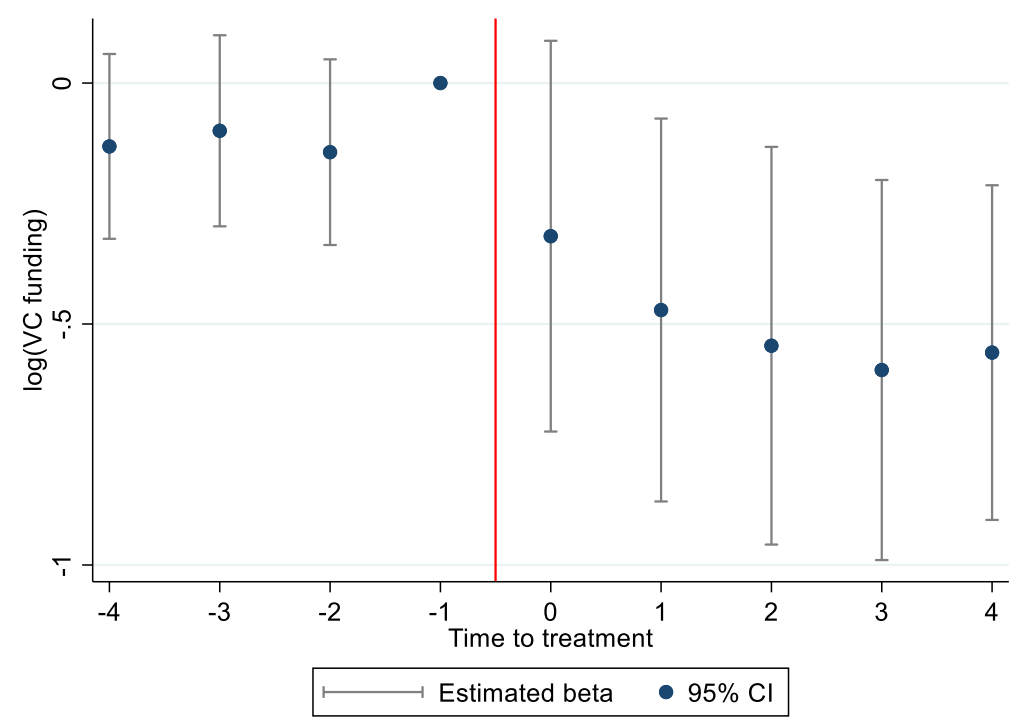

Notes: Dependent variable: Firm-level VC funding volume. Results of the generalized event study; effect of change in legislation, taking treatment intensity into account. " 0 ": time of change in legislation. " $t$ ": leads. " $t$ ": lags. 95\% confidence intervals. Corresponding estimates: (Table 17, column 4; appendix).

The estimator for $L C B$ years indicates a significant positive relationship. In contrast to my results, Da Rin et al. (2006) do not find significant effects for either temporal restriction on losses. Surprisingly, the coefficient for relative restrictions on LCFs, LCF limit, is also positive and significant. Limitations on the offset of losses should reduce the value of LCFs and therefore, if anything, reduce investment. Similar to other studies, the significant negative estimate for CGT translates into a $-6.8 \%$ decrease in VC funding for a $10 \%$ increase in the capital gains tax rate. ${ }^{28}$ In line with expectations, higher unemployment, proxying adverse economic conditions, and high inflation are associated with lower VC funding.

On the firm level, all three control variables are highly statistically significant. The results indicate that smaller and younger firms receive more funding. The amount of LCFs positively affects the level of investment; in other words, VC investors seem to value these tax assets' expected value, albeit the estimated effect size is relatively small. This finding supports my hypotheses, as the consideration of LCFs in the decision-making process is a pre-requisite for anti-tax loss trafficking regulations to matter.

\footnotetext{
${ }^{28}$ Edwards and Todtenhaupt (2020) investigate the exemption of capital gains in the US, which reduced the maximum tax on capital gains from $15 \%$ to $0 \%$. They estimate an increase in VC funding of roughly $12 \%$ to $14 \%$ in response to the change in legislation. A direct comparison to existing country-level studies on VC financing is difficult, as the specific definition of VC as dependent variable differs widely. However, e.g. Da Rin et al. (2006) estimate that large increases in the capital gain tax rate decreases normalized high-tech PE investment by $22 \%$.
} 
Table 3: Generalized DiD results, restriction category, combined analysis

\begin{tabular}{|c|c|c|c|c|}
\hline & \multicolumn{4}{|c|}{$\begin{array}{c}\text { I - Restriction category } \\
\log (\mathrm{VC} \text { funding })\end{array}$} \\
\hline & 1 & 2 & 3 & 4 \\
\hline Restriction category & $-0.403 * * *$ & $-0.229 * *$ & $-0.438 * * *$ & $-0.435 * * *$ \\
\hline Escape clause & & & 0.081 & 0.088 \\
\hline LCF years & & & 0.003 & 0.004 \\
\hline LCB years & & & $0.126^{* * *}$ & $0.125 * * *$ \\
\hline LCF limit & & & $0.343 * * *$ & $0.354 * * *$ \\
\hline CIT & & & -0.012 & -0.014 \\
\hline$\Delta \mathrm{CIT}$ & & & -0.012 & -0.013 \\
\hline CGT & & & $-1.074 * *$ & $-1.128 * * *$ \\
\hline DIT & & & -0.255 & -0.243 \\
\hline GDP per capita & & & 0.000 & 0.000 \\
\hline GDP growth & & & 0.011 & 0.010 \\
\hline Unemployment & & & $-0.042 * * *$ & $-0.042 * * *$ \\
\hline Inflation & & & $-0.067 * *$ & $-0.066 * *$ \\
\hline EIF amount & & & -0.000 & -0.000 \\
\hline EIF number & & & 0.000 & 0.000 \\
\hline Lagged Public PE & & & 0.000 & 0.000 \\
\hline Lagged total assets & & & & $-0.000 * * *$ \\
\hline Age & & & & $-0.063 * * *$ \\
\hline LCF amount (1 yr) & & & & $0.000 * * *$ \\
\hline Firm FE & Yes & Yes & Yes & Yes \\
\hline Year FE & & Yes & Yes & Yes \\
\hline \# Observations & 17,331 & 17,331 & 17,331 & 17,331 \\
\hline Adj. R-squared & 0.001 & 0.008 & 0.009 & 0.011 \\
\hline
\end{tabular}

Notes: Results linear generalized DiD regression of restriction category (see Table 1) on the logarithm of VC funding volume received. Categories range from 0 to 4 , a higher restriction category implies more restrictive antitax loss trafficking rules. Controls as indicated. Definition of variables: Table 11 (appendix). *, **, and $* * *$ indicate significance at the 10,5 , and $1 \%$ level. Standard errors: Clustered at country level.

To relate the results to the case studies previously conducted, I replace the Restriction Category with dummy variables for each legislation change. In the respective countries, the dummy is equal to one at the time of change and the following periods, and zero otherwise. Insufficient accounting information before 2006 limits the number of changes that I can explore. ${ }^{29}$ As apparent in Table 4, the main effect is identified by introducing cumulative regimes in Hungary and Croatia and shifting to an ownership-based restriction in Germany. The direction of the

\footnotetext{
${ }^{29}$ While I am able to match most of the names of VC-funded companies to company names in Orbis, almost all of them are missing accounting data from 1998 to 2006 . Only $2 \%$ of the observations in the panel sample date before 2006.
} 
coefficients aligns with expectations, ${ }^{30}$ albeit the estimates' size is far larger and more significant than in the case studies. The estimated decreases amount to $-66.1 \%$ (Germany), $-24.0 \%$ (Hungary), and $-50.4 \%$ (Croatia).

Table 4: Generalized DiD results, country dummies, combined analysis

\begin{tabular}{lcccc}
\hline & \multicolumn{5}{c}{$\begin{array}{c}\text { II - Country dummy } \\
\log (\mathbf{V C} \text { funding) }\end{array}$} \\
\hline & 1 & 2 & 3 & 4 \\
\hline CZ & 0.000 & $-0.483^{* *}$ & -0.370 & -0.272 \\
DE & $-0.937 * * *$ & $-0.623 * * *$ & $-1.090^{* * *}$ & $-1.083^{* * *}$ \\
GR & $-0.428 * * *$ & $-0.127 *$ & 0.309 & 0.328 \\
HU (2012) & $0.080^{* * *}$ & $0.454^{* * *}$ & $-0.262^{* *}$ & $-0.275^{*}$ \\
HR & $-0.984 * * *$ & $-0.743 * * *$ & $-0.703^{* * *}$ & $-0.702^{* * *}$ \\
\hline Country-level controls & & & Yes & Yes \\
Firm-level controls & & & & Yes \\
Firm FE & Yes & Yes & Yes & Yes \\
Year FE & & Yes & Yes & Yes \\
\hline \# Observations & 17,331 & 17,331 & 17,331 & 17,331 \\
Adj. R-squared & 0.001 & 0.008 & 0.009 & 0.010 \\
\hline
\end{tabular}

Notes: Results linear generalized DiD regressions of legislation change dummies on the logarithm of VC funding volume received. Legislation change dummies equal 1 in the year when anti-tax loss trafficking rules changed and all following years in the country specified, and 0 otherwise. Controls as indicated. Definition of variables: Table 11 (appendix). *,**, and $* * *$ indicate significance at the 10,5 , and $1 \%$ level. Standard errors: Clustered at country level.

As already mentioned, the restriction to full information on the firm-level control variables poses a severe limitation. These results underline the sample selection bias inherent in the combined analysis. The stronger effects indicate that the sub-sample with complete coverage of the required accounting variables is particularly affected by anti-tax loss trafficking rules. The excluded companies are relatively young ( $42 \%$ are aged up to five years, $71 \%$ up to ten years). Based on the data, it is impossible to determine any other differences in characteristics between the selected and the excluded companies beyond this aspect. Any conclusions drawn from the panel analysis results have to be evaluated in light of this limitation: The companies driving the negative estimates are likely more mature and thus at a later VC financing stage where tax aspects might be more relevant compared to very early funding rounds.

\footnotetext{
${ }^{30}$ In Hungary, the coefficient is positive and highly significant before controlling for time-varying country-specific factors. This can be attributed to the launch of JEREMIE (Joint European Resources for Micro to Medium Enterprises) VC funds in 2010, 2012 and 2013, right around the time of the introduction of the cumulative regime.
} 


\subsection{Heterogeneity Analyses}

I extend the main analysis results by exploring whether the effects depend on the companies' characteristics. I focus on the funding volume received (section 5.4.1), age (section 5.4.2), and industry affiliation (section 5.4.3) of the funded firms.

\subsubsection{Funding Volume}

To further analyze these findings, I split the sample based on the total VC funding received by a company. ${ }^{31}$ I divide sub-samples into companies receiving a total VC funding volume below the $25^{\text {th }}$ percentile, between the $25^{\text {th }}$ and $50^{\text {th }}$ percentile, between the $50^{\text {th }}$ and $75^{\text {th }}$ percentile, and above the $75^{\text {th }}$ percentile. The summary statistics in Table 5 shows that companies in the lowest percentile are, on average, much bigger and also older compared to the others. By contrast, companies in the highest percentile report considerably higher losses.

Table 5: Descriptive statistics, VC funding volume percentiles

\begin{tabular}{|c|c|c|c|c|c|c|}
\hline Variable & Obs & Std. Dev. & Min & Mean & Median & Max \\
\hline \multicolumn{7}{|l|}{ Panel 1: Below 25\% } \\
\hline VC funding & 10074 & 51.29 & 0.00 & 8.12 & 0.00 & 500.00 \\
\hline Total Assets & 10074 & $18,251.46$ & 0.00 & 646.28 & 3.62 & $1,206,064.00$ \\
\hline LCF amount (1 yr) & 10074 & 362.57 & $-19,660.24$ & -13.45 & 0.00 & 0.00 \\
\hline Age & 10074 & 8.05 & 0.00 & 10.94 & 10.00 & 165.00 \\
\hline \multicolumn{7}{|c|}{ Panel 2: $25 \%$ to $50 \%$} \\
\hline VC funding & 2645 & 360.22 & 0.00 & 153.35 & 0.00 & $1,514.16$ \\
\hline Total Assets & 2645 & 284.51 & 0.00 & 39.49 & 1.66 & $7,850.00$ \\
\hline LCF amount (1 yr) & 2645 & 49.07 & $-1,624.00$ & -2.43 & 0.00 & 0.00 \\
\hline Age & 2645 & 7.77 & 0.00 & 9.10 & 7.00 & 78.00 \\
\hline \multicolumn{7}{|c|}{ Panel 3: $50 \%$ to $75 \%$} \\
\hline VC funding & 2634 & $1,103.47$ & 0.00 & 474.61 & 0.00 & $5,188.70$ \\
\hline Total Assets & 2634 & 618.21 & 0.00 & 88.80 & 2.89 & $9,269.00$ \\
\hline LCF amount (1 yr) & 2634 & 67.53 & $-2,757.00$ & -4.19 & -0.03 & 0.00 \\
\hline Age & 2634 & 6.56 & 0.00 & 8.32 & 7.00 & 58.00 \\
\hline \multicolumn{7}{|c|}{ Panel 4: Above $75 \%$} \\
\hline VC funding & 2037 & $5,644.30$ & 0.00 & $2,120.07$ & 0.00 & $120,946.05$ \\
\hline Total Assets & 2037 & $2,212.13$ & 0.00 & 220.31 & 7.42 & $42,751.00$ \\
\hline LCF amount (1 yr) & 2037 & 741.35 & $-16,289.00$ & -54.56 & -0.16 & 0.00 \\
\hline Age & 2037 & 6.32 & 0.00 & 9.16 & 8.00 & 56.00 \\
\hline
\end{tabular}

Notes: Summary statistics for firm-level variables, as defined in Table 11 (appendix). Panel 1: Companies with total VC funding volume below $25^{\text {th }}$ percentile. Panel 2: Companies with total VC funding volume between $25^{\text {th }}$ and $50^{\text {th }}$ percentile. Panel 3: Companies with total VC funding volume between $50^{\text {th }}$ and $75^{\text {th }}$. Panel 4: Companies with total VC funding volume above $75^{\text {th }}$ percentile.

Figure 8 depicts the coefficients for Restriction category, estimated based on specification I-4 in the different sub-samples. With increasing VC funding volume, the estimates get less precise

\footnotetext{
${ }^{31}$ I add up the funding volume received by a company across all rounds and years. The distribution of total VC funding per company is highly left skewed with a median of 7.86th€ and a mean of $1,871.32$ th€.
} 
as apparent from broader confidence intervals. All coefficient estimates are negative. Generally, the coefficients increase in the VC funding volume, albeit start-ups between the $25^{\text {th }}$ and $50^{\text {th }}$ percentile seem the most severely affected. Here, the average decrease is estimated at $-79.1 \%$.

\section{Figure 8: Estimates in sub-samples based on VC funding volume percentile}

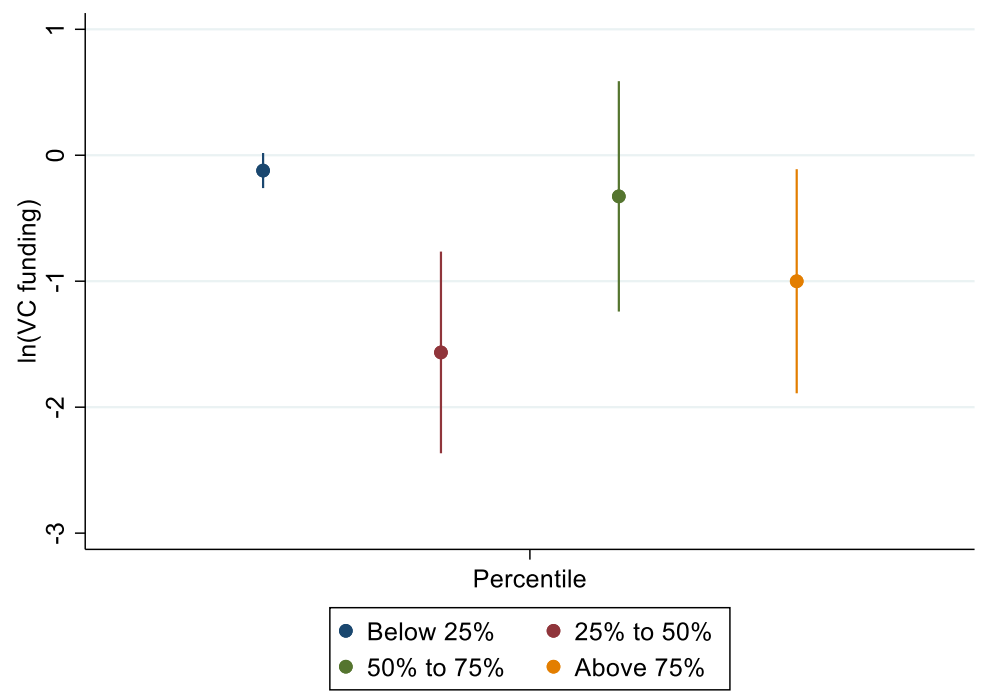

Notes: Results linear generalized DiD regressions of restriction category (see Table 1) on the logarithm of VC funding volume received based on specification I-4. Categories range from 0 to 4 , a higher restriction category implies more restrictive anti-tax loss trafficking rules. Sub-samples: Split based on percentiles of total VC funding volume as indicated. 95\% confidence intervals. Descriptive statistics and corresponding estimates: Table 5 and Table 18 in the appendix.

The significant estimates below the $25^{\text {th }}$ percentile and above the $75^{\text {th }}$ percentile translate into effects of $-11.4 \%$ and $-63.2 \%$, respectively.VC investors do not seem to care that much about anti-tax loss trafficking rules until they invest larger sums (the mean of total VC funding volume below the $25^{\text {th }}$ percentile amounts to $€ 8.000$ ). Conceptually, this is convincing as lower sums entail, on an absolute level, lower risk for the investor.

\subsubsection{Age Structure}

The majority of the sample start-ups are aged below or up to ten years (65.64\%). Around a quarter of the companies is older than ten years. Over the time horizon included in their sample (1993 to 1999), Cooper and Knittel (2010) show that firms aged up to five years increasingly reported tax losses, particularly in the information and professional services sector. The overall share of losses remained below the percentage reported for older companies, on average. In contrast, the young firms required comparatively more time to offset their losses and had lower utilization rates. All in all, they find that new firms are more greatly affected by the asymmetric treatment of tax losses. Therefore, tax loss transfer restrictions could more severely impair VC funding of young companies than mature firms. However, the closer investors approach the exit, 
the divestment's potential consequences get in the focus. While tax structuring might not be as relevant in earlier investment stages, it might gain importance down the road.

Table 6: Descriptive statistics, different age groups

\begin{tabular}{|c|c|c|c|c|c|c|}
\hline Variable & Obs & Std. Dev. & Min & Mean & Median & Max \\
\hline \multicolumn{7}{|c|}{ Panel 1: Age 0 to 5 years } \\
\hline VC funding & 4541 & $2,004.45$ & 0.00 & 508.36 & 0.00 & $28,603.67$ \\
\hline Total Assets & 4541 & $17,949.66$ & 0.00 & 403.75 & 0.97 & $1,206,064.00$ \\
\hline LCF amount (1 yr) & 4541 & 456.46 & $-19,660.24$ & -25.04 & -0.06 & 0.00 \\
\hline Age & 4541 & 1.39 & 0.00 & 3.24 & 3.00 & 5.00 \\
\hline \multicolumn{7}{|c|}{ Panel 2: Age 5 to 10 years } \\
\hline VC funding & 7100 & $2,584.36$ & 0.00 & 430.71 & 0.00 & $120,946.05$ \\
\hline Total Assets & 7100 & $1,230.07$ & 0.00 & 101.37 & 2.84 & $42,751.00$ \\
\hline LCF amount (1 yr) & 7100 & 406.93 & $-16,289.00$ & -17.18 & -0.01 & 0.00 \\
\hline Age & 7100 & 1.65 & 5.00 & 7.45 & 7.00 & 10.00 \\
\hline \multicolumn{7}{|c|}{ Panel 3: Age 10 to 15 years } \\
\hline VC funding & 5027 & $1,796.12$ & 0.00 & 223.90 & 0.00 & $55,000.00$ \\
\hline Total Assets & 5027 & 977.49 & 0.00 & 91.39 & 5.09 & $28,420.00$ \\
\hline LCF amount (1 yr) & 5027 & 145.58 & $-9,784.51$ & -4.59 & 0.00 & 0.00 \\
\hline Age & 5027 & 1.67 & 10.00 & 12.20 & 12.00 & 15.00 \\
\hline \multicolumn{7}{|c|}{ Panel 4: Age above 15 years } \\
\hline VC funding & 3391 & $1,134.10$ & 0.00 & 160.17 & 0.00 & $20,145.96$ \\
\hline Total Assets & 3391 & $23,615.85$ & 0.00 & $1,358.25$ & 9.20 & $676,747.00$ \\
\hline LCF amount (1 yr) & 3391 & 431.50 & $-15,642.50$ & -14.80 & 0.00 & 0.00 \\
\hline Age & 3391 & 10.24 & 15.00 & 20.74 & 18.00 & 165.00 \\
\hline
\end{tabular}

Notes: Summary statistics for firm-level variables, as defined in Table 11 (appendix). Panel 1: Companies aged up to five years. Panel 2: Companies aged between five and ten years. Panel 3: Companies aged between ten and 15 years. Panel 4: Companies aged above 15 years.

The negative coefficients for the age variable in previous regressions already indicate that, on average, older companies receive less funding. Therefore, I subdivide the sample into four categories based on five-year age groups. Table 6 depicts the descriptive statistics. As already found in previous specifications, younger companies receive, on average, higher VC funding and carry higher losses. However, there are apparent size differences. The first age group (zero to five years) has, on average, more than triple the amount of assets than each of the following two age groups (five to 15 years), but less than a third than the last age group (above 15 years).

Overall, the age of a company seems to matter not only for the VC funding volume, besides other factors, but also for the severity of VC funding impairment in response to the introduction of anti-tax loss trafficking rules (Figure 9). Estimates for Restriction category are all negative but vary in size and significance between the age groups. I find the strongest effect for the age group between ten and 15 years. For these companies, the exit time is likely near, so investors start to incorporate the additional risk due to transfer restrictions in their decision process. 


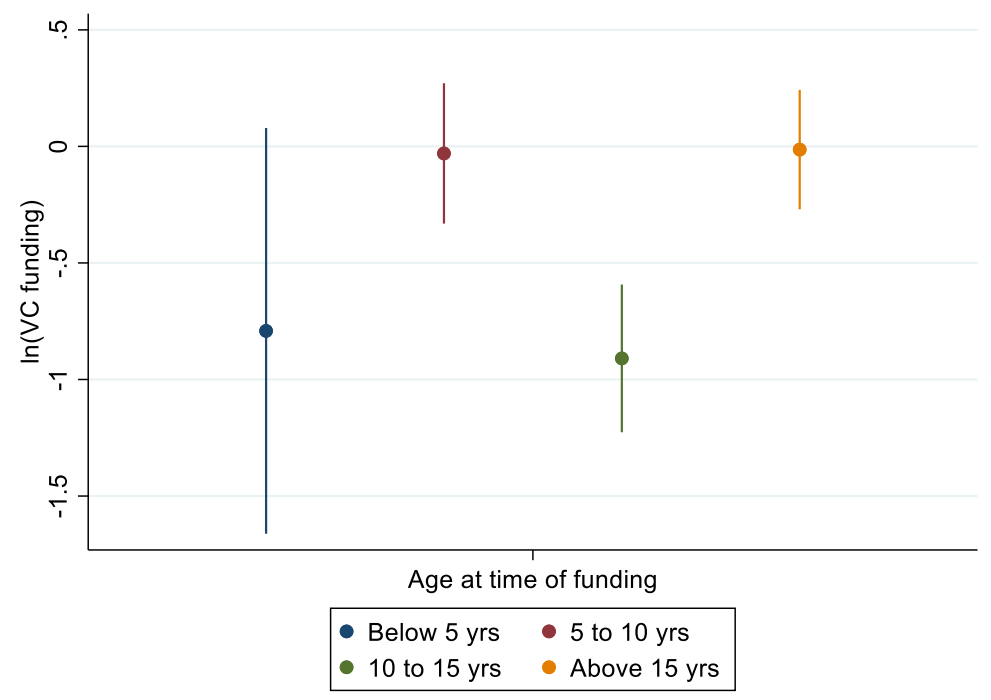

Notes: Results linear generalized DiD regressions of restriction category (see Table 1) on the logarithm of VC funding volume received based on specification I-4. Categories range from 0 to 4 , a higher restriction category implies more restrictive anti-tax loss trafficking rules. Sub-samples: Split based on age as indicated. $95 \%$ confidence intervals. Descriptive statistics and corresponding estimates: Table 6 and Table 19 in the appendix.

Table 7: Generalized DiD results, country dummies, age

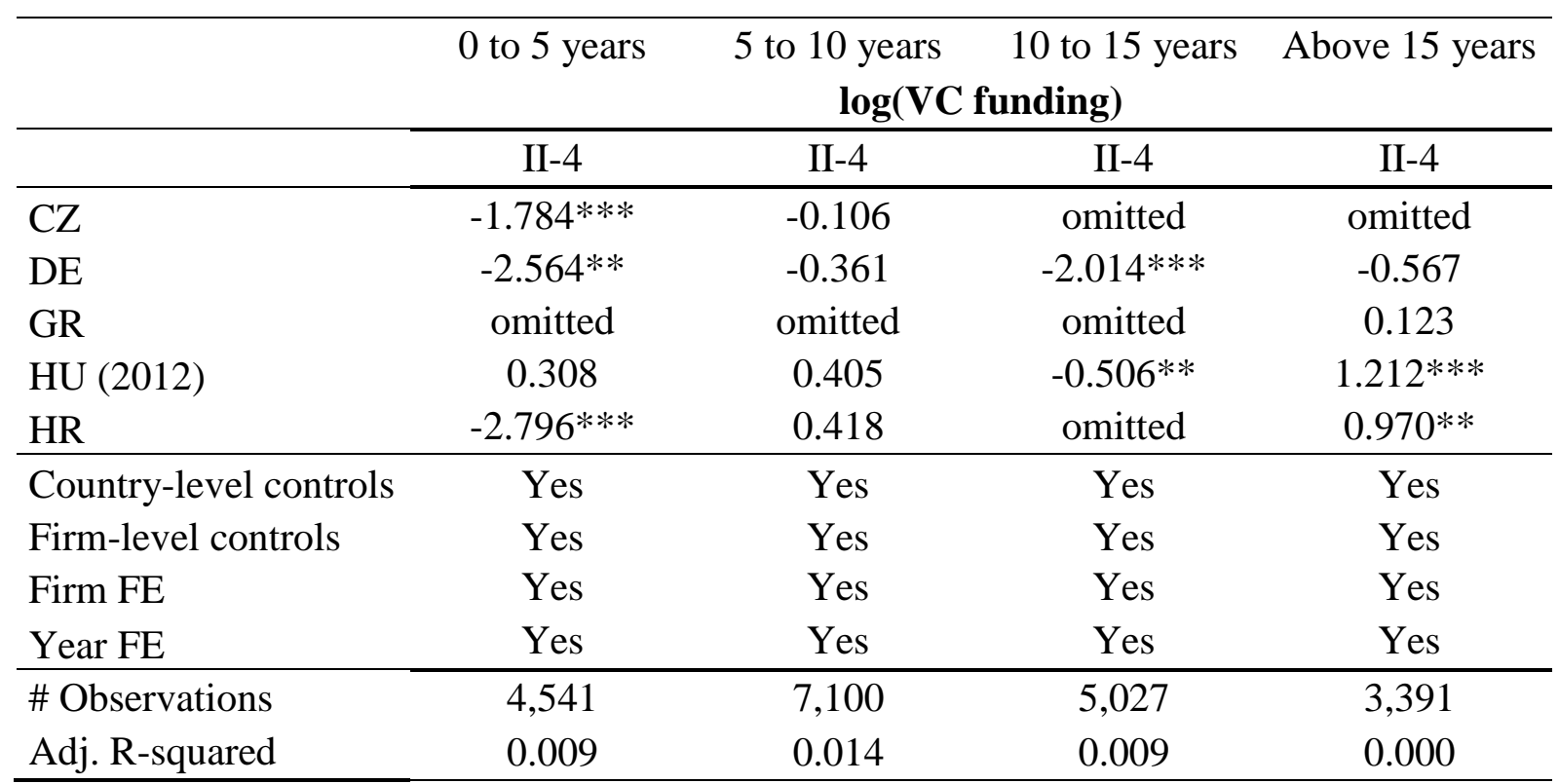

Notes: Results linear generalized DiD regressions of country dummies on the logarithm of VC funding volume received. Controls as indicated. Definition of variables: Table 11 (appendix). Differentiation depending on age of companies as indicated. *,**, and *** indicate significance at the 10,5 , and $1 \%$ level. Standard errors: Clustered at country level. "Omitted": Variable was omitted from the regression due to multi-collinearity.

Interestingly, the results suggest a shift of VC funding between the different age groups when focusing on individual changes (Table 7). In all sub-samples, the coefficients are negative for the regime changes in the Czech Republic and Germany. However, in Hungary and Croatia, funds seem to have been shifted from younger to older companies: The significant estimates are negative in younger age groups but turn positive for the oldest companies. The positive 
coefficients cause the overall insignificant impact of Restriction Category. Investors choosing to invest in comparatively less risky companies at later development stages could explain these opposing effects.

\subsubsection{Industry Heterogeneity}

So far, I have considered the impact of tax loss restrictions across all sectors. Research shows that industries differ in loss probabilities and the use of LCFs. The proprietary data used in Cooper and Knittel (2010) shows differences between reported tax losses as well as their utilization. Dreßler and Overesch (2013) find cyclical effects in the probability of making losses, which is more pronounced in some sectors (e.g., data processing) compared to others (e.g., food). All in all, the literature suggests that anti-tax loss regulations will have different effects, depending on the industry-specific relevance of LCFs.

Although the firm fixed effects employed in all specifications should account for industry-specific characteristics, it could still be worthwhile to investigate the diverging impact on a broader basis. For this purpose, I employ Eurostat's high-tech aggregation system to differentiate between low- and high-tech industries. I define high- and medium-high-technology manufacturing sectors and high-tech knowledge-intensive services as high-tech industries. (Table 20 in the appendix). I classify all other companies as part of low-tech sectors. Comparing the means in the low- to the high-tech sample (Table 8) shows that start-ups in high-tech industries are, on average, considerably smaller, younger, carry higher estimated LCFs, and receive more VC funding.

Table 8: Descriptive statistics, low-vs. high-tech industries

\begin{tabular}{lcccccc}
\hline Variable & Obs & Std. Dev. & Min & Mean & Median & Max \\
\hline Panel 1: Low-tech companies & & & & & \\
\hline VC funding & 9,358 & $1,743.47$ & 0.00 & 312.87 & 0.00 & $33,896.11$ \\
Total Assets & 9,358 & $18,936.78$ & 0.00 & 702.23 & 4.18 & $1,206,064.00$ \\
LCF amount (1 yr) & 9,358 & 375.19 & $-19,660.24$ & -13.69 & 0.00 & 0.00 \\
Age & 9,358 & 8.68 & 0.00 & 10.68 & 9.00 & 165.00 \\
\hline Panel 2: High-tech companies & & & & & \\
\hline VC funding & 7,895 & $2,456.92$ & 0.00 & 395.17 & 0.00 & $120,946.05$ \\
Total Assets & 7,895 & $1,173.52$ & 0.00 & 91.58 & 2.70 & $42,751.00$ \\
LCF amount (1 yr) & 7,895 & 381.39 & $-16,289.00$ & -17.22 & -0.03 & 0.00 \\
Age & 7,895 & 6.27 & 0.00 & 9.34 & 8.00 & 86.00 \\
\hline
\end{tabular}

Notes: Summary statistics for firm-level variables, as defined in Table 11 (appendix). Panel 1: Companies in lowtech industries. Panel 2: Companies in high-tech industries. Definition of industries: Table 20 (appendix).

Figure 10 depicts the regression results for the low- and high-tech sample. The low-tech industry coefficeient is less significant and closer to zero. In other words, firms in technologically more advanced industries are the ones that are severely affected. The high-tech sector 
results are slightly larger than the effect estimated in the main specification (Table 3). Anecdotal evidence confirms that tax loss transfer restrictions lead to a clear competitive disadvantage for investors in innovative sectors. ${ }^{32}$

\section{Figure 10: Estimates in sub-samples based on industry}

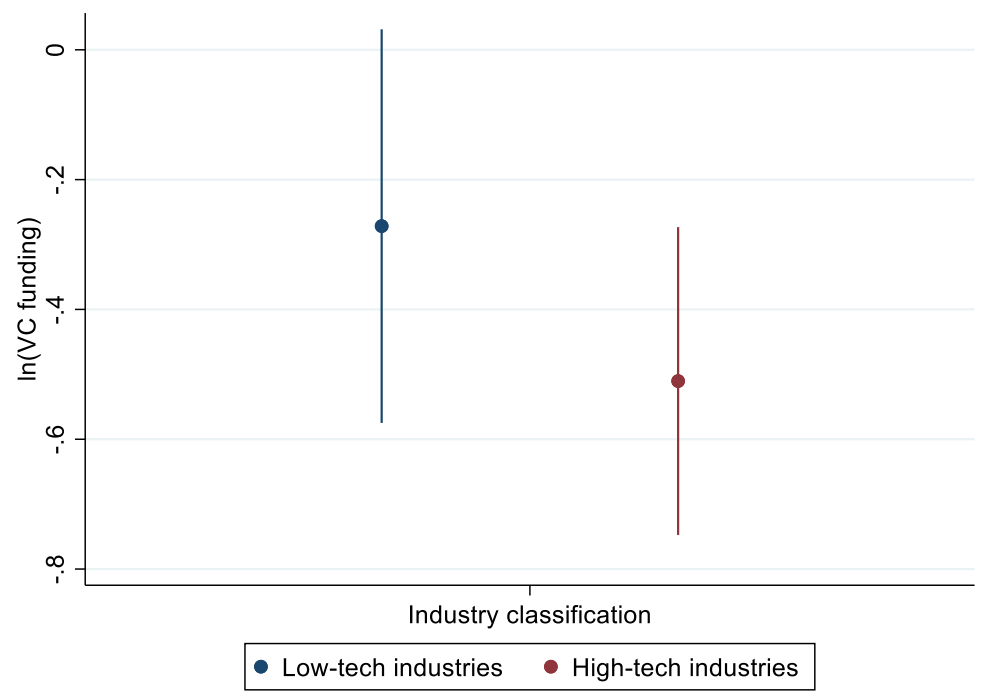

Notes: Results linear generalized DiD regressions of restriction category (see Table 1) on the logarithm of VC funding volume received based on specification I-4. Categories range from 0 to 4 , a higher restriction category implies more restrictive anti-tax loss trafficking rules. Sub-samples: Split based on age as indicated. 95\% confidence intervals. Descriptive statistics and corresponding estimates: Table 8 and Table 21 in the appendix.

\subsection{Robustness Checks}

I conduct several tests to confirm my results: I repeat the main analysis with a non-linear model, the Poisson pseudo maximum likelihood (PPML) estimator (section 5.5.1). I follow up with alternative approximation methods for a firm's LCFs (section 5.5.2).

\subsubsection{Alternative Model: Poisson}

The data employed for the empirical analysis contains, by construction, a high share of zeros recorded for VC funding (89.89\% of the company-year observations). To account for the highly skewed distribution, I employ the PPML estimator proposed by Silva and Tenreyro (2006). ${ }^{33}$ Analogously to the main specification, I apply formula (4).

\footnotetext{
${ }^{32}$ Research in areas such as biotechnology commonly requires large up-front investment and entails high risk. Thoughout the investment stages, the start-ups are generally in a loss position, triggering anti-tax loss trafficking rules when ownership changes during fundraising rounds or investor exits: NVCA, https://nvca.org/pressreleases/nvca-cheers-prioritization-startup-loss-carryforward-rule-reforms/ (05.11.2020). In addition, if projects fail, large companies can offset their losses with other profits. By contrast, VC investors cannot recover their losses from investments in small start-ups: FAZ, https://www.faz.net/aktuell/wirtschaft/unternehmen/wiehelmut-jeggle-ueber-die-biontech-aktie-denkt-17007068.html (19.10.2020).

${ }_{33}^{33}$ Poisson models are generally chosen in a setting with count variables on the left hand side of the equation, whereas the application of a pseudo-maximum likelihood estimator allows for a more general application (Shepherd, 2016).
} 
Table 9 depicts the results. The number of observations amounts to roughly half compared to the linear model. The coefficients for the restriction categories are negative and highly significant. However, estimates are larger than in the corresponding linear estimate (Table 3). Moving from a lower to a higher restriction category translates into a decrease in VC funding of around 52.2\%. The control variables' coefficients (except for age) also align in size and significance with the estimates in the main analysis.

Table 9: Poisson pseudo maximum likelihood estimation

\begin{tabular}{|c|c|c|c|c|}
\hline & & $\begin{array}{r}\text { I - Restr } \\
\log (V\end{array}$ & $\begin{array}{l}\text { category } \\
\text { ading) }\end{array}$ & \\
\hline & 1 & 2 & 3 & 4 \\
\hline Restriction category & $-0.607 * * *$ & $-0.346 * *$ & $-0.702 * * *$ & $-0.650 * * *$ \\
\hline Escape clause & & & -0.001 & 0.027 \\
\hline LCF years & & & 0.010 & 0.020 \\
\hline LCB years & & & $0.152 * * *$ & $0.129 * * *$ \\
\hline LCF limit & & & $0.579 * * *$ & $0.561 * * *$ \\
\hline CIT & & & -0.006 & -0.004 \\
\hline$\Delta \mathrm{CIT}$ & & & -0.024 & -0.021 \\
\hline CGT & & & $-1.629 * * *$ & $-1.415 * *$ \\
\hline DIT & & & -0.058 & -0.325 \\
\hline GDP per capita & & & $0.000 * *$ & $0.000 *$ \\
\hline GDP growth & & & 0.032 & 0.025 \\
\hline Unemployment & & & $-0.056 * *$ & $-0.063 * * *$ \\
\hline Inflation & & & $-0.117 * *$ & $-0.121 * *$ \\
\hline EIF amount & & & $-0.001 * *$ & $-0.000 * *$ \\
\hline EIF number & & & $0.000 * *$ & $0.000 * *$ \\
\hline Lagged Public PE & & & 0.000 & 0.000 \\
\hline Lagged total assets & & & & -0.000 \\
\hline Age & & & & $-6.256 * * *$ \\
\hline LCF amount (1 yr) & & & & -0.001 \\
\hline Firm FE & Yes & Yes & Yes & Yes \\
\hline Year FE & & Yes & Yes & Yes \\
\hline \# Observations & 8,859 & 8,805 & 8,805 & 8,805 \\
\hline Adj. R-squared & 0.0908 & 0.107 & 0.113 & 0.124 \\
\hline
\end{tabular}

Notes: Results Poisson pseudo-maximum likelihood regressions of restriction category (see Table 1) on the VC funding volume received in its logarithm. Categories range from 0 to 4 , a higher restriction category implies more restrictive anti-tax loss trafficking rules. Controls as indicated. Definition of variables: Table 11 (appendix). *, **, and $* * *$ indicate significance at the 10,5 , and $1 \%$ level. Standard errors: Clustered at country level.

\subsubsection{Alternative Loss Carryforward Definitions}

So far, LCFs have been calculated based on the preceding year's profits (LCF amount ( 1 yr)). Alternatively, LCFs can be calculated incorporating more periods. Also, instead of including the amount of LCFs available, a dummy variable set equal to one if a LCF is available and zero otherwise can be defined. Rechbauer (2017) investigates the LCF proxies employed in the literature and shows that methods relying on accounting data might not identify the true amount 
of LCFs. She demonstrates that the rate of correct predictions is higher if she approximates LCFs with a 0/1 dummy. Calculating the actual amount of LCFs instead of only defining their existence is found to be subject to greater estimation error. The majority of empirical studies basing LCF variables on financial statement information use a dummy predicted from the preceding year's earnings (Haring, Niemann, \& Runger, 2012; Krämer, 2015; Merz \& Overesch, 2016). I construct LCF amounts and dummies based on the preceding two and four years and re-run the main specification in alternative specifications. My calculations follow Bernasconi, Marenzi, and Pagani’s (2005) method. ${ }^{34}$

Table 10: Generalized DiD results, alternative $L C F^{*}$ definitions

\begin{tabular}{lcc}
\hline & \multicolumn{3}{c}{$\begin{array}{c}\text { I -Restriction category } \\
\log (\mathbf{V} \text { C funding) }\end{array}$} \\
\hline & 4 & \\
\hline Panel 1: One year & & \\
\hline LCF amount & $-0.435^{* * *}$ & 17,331 \\
LCF dummy & $-0.435^{* * *}$ & 17,331 \\
\hline Panel 2: Two years & & 12,591 \\
\hline LCF amount & $-0.249^{* *}$ & 12,591 \\
LCF dummy & $-0.249^{* *}$ & \\
\hline Panel 3: Four years & & 6,968 \\
\hline LCF amount & 0.204 & 6,968 \\
LCF dummy & 0.203 & \\
\hline
\end{tabular}

Notes: Notes: Results linear generalized DiD regressions of anti-tax loss trafficking rules on the VC funding volume received. "Restriction category": As defined in Table 1. Categories range from 0 to 4, a higher restriction category implies more restrictive anti-tax loss trafficking rules. Full set of controls included. Definition of variables: Table 11 (appendix). Panel 1: 1-year-based LCF measures. Panel 2: 2-year-based LCF measures. Panel 3: 4-yearbased LCF measures. *, **, and *** indicate significance at the 10,5 , and $1 \%$ level. Standard errors: Clustered at country level.

Table 10 presents the results for estimated LCF amounts and the related LCF dummies. For reference, the first group in Panel 1 shows the main regression results (as stated in Table 3). In neither panel, the results change when exchanging the amount of LCFs for a binary dummy variable. Choosing between the presence of LCFs instead of their size seems only marginally to affect the results. Extending the time horizon decreases the estimate for two-year-based measures (Panel 2). The coefficients turn positive and insignificant when taking four years into account (Panel 3).

However, extending the period for LCF calculations also decreases the sample size. The measures' construction necessitates two respective four years of non-missing information on profits and losses before taxes. Around $20 \%$ of the companies observed are younger than five

\footnotetext{
${ }^{34}$ Please refer to appendix A3 for a calculation example.
} 
years. If especially newly created companies carry losses (since they are yet not profitable), anti-tax loss trafficking rules will be particularly relevant for younger companies. Extending the requirements for the availability of accounting information will exclude precisely those cases. Also, if there are shifting effects from recently established to older companies or vice versa, extending the required number of years and contiguous non-missing accounting information will bias the results.

\section{Summary and Discussion}

Anti-tax loss trafficking rules have been criticized for deterring start-up financing by VC investors. The potential disallowance of the use of LCFs increases the investment risk, as accumulated losses could end up not being tax-deductible. Since young innovative companies are considered an important driver of a country's economic development, such obstacles should be eliminated to foster a vibrant environment for entrepreneurship.

In this study, I have investigated the effect of restrictions on the transfer of tax losses after a change in ownership or activity on VC funding. I expected anti-tax loss trafficking regulations to impair start-up financing and more lenient restrictions to have a smaller effect. To test my hypotheses, I conducted individual case studies as well as a combined analysis. I employed a DiD design to analyze the relationship between anti-tax loss trafficking rules and the VC funding volume in the EU28 Member States. An event study approach accompanied these analyses. I find that anti-tax loss trafficking rules indeed negatively affect the $\mathrm{VC}$ funding volume received by start-ups. The coefficient is statistically and economically significant, supporting my first hypothesis. With an estimated average decrease of more than $-35.5 \% \%$, the effect's magnitude is also economically significant. Stricter regulation types seem to drive the results.

I do not consider reverse causality to be a problem in my setting. Anti-tax loss trafficking rules target tax-motivated acquisitions, where companies without economic activity are bought only because of their LCFs. Adverse impacts on VC transactions are unintended side effects, but they are commonly not named the reason for changes in legislation. The lack of consideration of the VC market in this context already shows in the exemptions granted, which usually target large companies that are quoted, part of a group, or undergo financial rehabilitation.

I extend the analysis by investigating the impact on the $\mathrm{VC}$ funding, depending on the total funding volume a company received, age, and industry affiliation. All extensions reveal heterogeneous effects: First, highly-funded companies tend, on average, to be more severely affected than those that received only little VC funding. Second, VC investors decrease investments in 
response to tax loss transfer restrictions more strongly in older companies. If the investor's exit approaches, tax factors might be considered more important for the investment decision than during evaluations in earlier stages. There also seems to be a shift in VC funding from younger to older companies after introducing regimes that deny loss carryforwards after a cumulative change in ownership and activity. Third, my findings suggest that companies in high-tech industries are predominantly affected.

The main results also hold when applying a Poisson model. In the main specification, I use profits and losses of the previous period to construct a measure of each companies' LCF. Extending this time horizon, which requires several years of profit and loss data for the observed companies, weakens the results. However, the additional constraint leads to a decrease in sample size and the exclusion of very young companies. Both could explain the reduced size and significance of the estimates.

Considering the negative effects, relaxing anti-tax loss trafficking restrictions could serve as one step towards improving funding possibilities for European start-ups. Although several EU28 Member States lessened their regulations over the years, as of 2018, six countries still deny the transfer of losses after a change in ownership (Bührle \& Spengel, 2020). Efforts have already been undertaken to prevent the anti-abuse regulations from unintentionally disadvantaging start-ups with high accumulated tax LCFs. Nevertheless, regulators should strive to explicitly exclude them from the scope of their rules while keeping the administrative burdens start-ups might face in this context to a minimum. While my analysis focuses on Europe, similar restrictions exist worldwide. In light of the Corona crisis, tax loss restrictions such as anti-tax loss trafficking rules could pose one element in a government's strategy to support the economy. First, the topic will gain relevance: losses are on the rise across industries. Second, anti-ax loss trafficking rules pose an even more pressing problem for innovative start-ups conducting highrisk research. In times where the world is eagerly awaiting a vaccine for Corona, VC funding for pharmaceutical start-ups should be promoted, not obstructed. 


\section{Appendix}

A1 Supplementary Tables

Table 11: Variable definition

\begin{tabular}{|c|c|}
\hline Variable & Description \\
\hline \multicolumn{2}{|l|}{ Dependent variable } \\
\hline $\log (V C$ funding $)$ & $\begin{array}{l}\text { Logarithm of VC funding received, measured in thousand } € \text {, win- } \\
\text { sorized at the } 1 \text { and } 99 \text { percent level (Source: VICO 4.0) }\end{array}$ \\
\hline \multicolumn{2}{|l|}{ Main variables of interest } \\
\hline Event & $\begin{array}{l}\text { Dummy that takes the value } 1 \text { in the period loss transfer re- } \\
\text { strictions are changed; } 0 \text { otherwise. Type of change as indicated } \\
\text { in the text (Source: Bührle \& Spengel (2020)) }\end{array}$ \\
\hline Treatment & $\begin{array}{l}\text { Treatment intensity; defined as the difference between the old } \\
\text { and new restriction category after a change in legislation } \\
\text { (Source: Bührle \& Spengel (2020)) }\end{array}$ \\
\hline Restriction category & $\begin{array}{l}\text { Loss transfer restriction category; Category } 0=\text { No explicit anti- } \\
\text { loss trafficking rule, } 1=\text { Denial of loss transfer after a change in } \\
\text { ownership and activity (cumulative), } 2=\text { Denial of loss transfer } \\
\text { after a change in activity, } 3=\text { Denial of loss transfer after a } \\
\text { change in ownership, } 4=\text { Denial of loss transfer after a change } \\
\text { in ownership or activity (see Table } 1 \text {; Source: Bührle \& Spengel } \\
(2020) \text { ) }\end{array}$ \\
\hline
\end{tabular}

Country-level controls

\begin{tabular}{ll}
\hline CIT & Statutory corporate income tax rate in \% (Source: European \\
& Commission) \\
& Change in CIT, i.e., CIT in t minus CIT in t-1 \\
CGT & Statutory capital gains tax rate in \% (Source: European Commis- \\
& sion) \\
& Statutory dividend income tax rate in \% (Source: European Com- \\
mission) & Dummy that takes the value 1 in the period anti-loss trafficking \\
Escape clause & rules incorporate escape clauses for listed companies, group re- \\
& structuring, recovery plans, hidden reserves, or the provision of
\end{tabular}


evidence for economic reasons; 0 otherwise (Source: Bührle \& Spengel (2020))

LCF years

Number of years a LCF is available, 50 if unlimited (Source: IBFD, tax guides)

LCB years

Number of years a LCB is available, 0 if not available (Source: IBFD, tax guides)

LCF limit

Dummy that takes the value 1 if relative restrictions apply to LCFs, 0 otherwise (Source: IBFD, tax guides)

GDP per capita

GDP per capita in thousand dollars, based on purchasing power parity and constant 2011 dollar (Source: World Bank)

GDP growth

Unemployment

Percentage growth rate of GDP at market prices, based on constant 2010 dollar (Source: World Bank)

Total unemployment, measured as percentage of total labor force (Source: World Bank)

Inflation

Inflation, measured as percentage change in consumer price index (Source: World Bank)

EIF amount

Amount of support provided by the EIF, all business lines (Source: EIF)

EIF number

Number of supported SMEs by the EIF, all business lines (Source: EIF)

Lagged PublicPE Amount of public PE investments with a one-year lag (Source: InvestEurope)

\begin{tabular}{ll}
\hline Firm-level controls & \\
\hline Lagged total assets & $\begin{array}{l}\text { Total assets recorded in the balance sheet, in million } € \text { and with } \\
\text { a one-year lag (Source: VICO 4.0, Orbis) }\end{array}$ \\
LCF amount (1 year) & LCF of company based on losses of the previous year (Source: \\
& VICO 4.0, Orbis) \\
Age & Age of the company (Source: VICO 4.0, Orbis)
\end{tabular}

Notes: Definition and source of variables employed in empirical specifications. 
Table 12: Categorization of anti-tax loss trafficking rules in the EU28, 1998-2014

\begin{tabular}{|c|c|c|c|c|c|c|c|c|c|c|c|c|c|c|c|c|c|}
\hline & 98 & 99 & 00 & 01 & 02 & 03 & 04 & 05 & 06 & 07 & 08 & 09 & 10 & 11 & 12 & 13 & 14 \\
\hline AT & 1 & 1 & 1 & 1 & 1 & 1 & 1 & 1 & 1 & 1 & 1 & 1 & 1 & 1 & 1 & 1 & 1 \\
\hline $\mathrm{BE}$ & 3 & 3 & 3 & 3 & 3 & 3 & 3 & 3 & 3 & 3 & 3 & 3 & 3 & 3 & 3 & 3 & 3 \\
\hline BG & 3 & 3 & 3 & 3 & 3 & 3 & 3 & 3 & 3 & 3 & 3 & 3 & 3 & 3 & 3 & 3 & 3 \\
\hline CY & 1 & 1 & 1 & 1 & 1 & 1 & 1 & 1 & 1 & 1 & 1 & 1 & 1 & 1 & 1 & 1 & 1 \\
\hline $\mathrm{CZ}$ & 0 & 0 & 0 & 0 & 0 & 0 & 1 & 1 & 1 & 1 & 1 & 1 & 1 & 1 & 1 & 1 & 1 \\
\hline $\mathrm{DE}$ & 1 & 1 & 1 & 1 & 1 & 1 & 1 & 1 & 1 & 1 & 3 & 3 & 3 & 3 & 3 & 3 & 3 \\
\hline DK & 3 & 3 & 3 & 3 & 3 & 3 & 3 & 3 & 3 & 3 & 3 & 3 & 3 & 3 & 3 & 3 & 3 \\
\hline $\mathrm{EE}$ & 0 & 0 & 0 & 0 & 0 & 0 & 0 & 0 & 0 & 0 & 0 & 0 & 0 & 0 & 0 & 0 & 0 \\
\hline ES & 3 & 3 & 3 & 3 & 3 & 3 & 3 & 3 & 3 & 3 & 3 & 3 & 3 & 3 & 3 & 3 & 3 \\
\hline FI & 3 & 3 & 3 & 3 & 3 & 3 & 3 & 3 & 3 & 3 & 3 & 3 & 3 & 3 & 3 & 3 & 3 \\
\hline FR & 2 & 2 & 2 & 2 & 2 & 2 & 2 & 2 & 2 & 2 & 2 & 2 & 2 & 2 & 2 & 2 & 2 \\
\hline GB & 1 & 1 & 1 & 1 & 1 & 1 & 1 & 1 & 1 & 1 & 1 & 1 & 1 & 1 & 1 & 1 & 1 \\
\hline GR & 0 & 0 & 0 & 0 & 0 & 0 & 0 & 0 & 0 & 0 & 0 & 0 & 0 & 0 & 0 & 0 & 3 \\
\hline HR & 0 & 0 & 0 & 0 & 0 & 0 & 0 & 0 & 0 & 0 & 0 & 0 & 1 & 1 & 1 & 1 & 1 \\
\hline $\mathrm{HU}$ & 3 & 3 & 3 & 0 & 0 & 0 & 0 & 0 & 0 & 0 & 0 & 0 & 0 & 0 & 1 & 1 & 1 \\
\hline IE & 1 & 1 & 1 & 1 & 1 & 1 & 1 & 1 & 1 & 1 & 1 & 1 & 1 & 1 & 1 & 1 & 1 \\
\hline IT & 1 & 1 & 1 & 1 & 1 & 1 & 1 & 1 & 1 & 1 & 1 & 1 & 1 & 1 & 1 & 1 & 1 \\
\hline LT & 0 & 0 & 0 & 0 & 1 & 1 & 1 & 1 & 1 & 1 & 1 & 1 & 1 & 1 & 1 & 1 & 1 \\
\hline LU & 0 & 0 & 0 & 0 & 0 & 0 & 0 & 0 & 0 & 0 & 0 & 0 & 0 & 0 & 0 & 0 & 0 \\
\hline LV & 1 & 1 & 1 & 1 & 1 & 1 & 1 & 1 & 1 & 1 & 1 & 1 & 1 & 1 & 1 & 1 & 1 \\
\hline MT & 0 & 0 & 0 & 0 & 0 & 0 & 0 & 0 & 0 & 0 & 0 & 0 & 0 & 0 & 0 & 0 & 0 \\
\hline NL & 3 & 3 & 3 & 1 & 1 & 1 & 1 & 1 & 1 & 1 & 1 & 1 & 1 & 1 & 1 & 1 & 1 \\
\hline PL & 0 & 0 & 0 & 0 & 0 & 0 & 0 & 0 & 0 & 0 & 0 & 0 & 0 & 0 & 0 & 0 & 0 \\
\hline PT & 2 & 2 & 2 & 2 & 2 & 2 & 2 & 2 & 4 & 4 & 4 & 4 & 4 & 4 & 4 & 4 & 4 \\
\hline RO & 0 & 0 & 0 & 0 & 0 & 0 & 0 & 0 & 0 & 0 & 0 & 0 & 0 & 0 & 0 & 0 & 0 \\
\hline SE & 3 & 3 & 3 & 3 & 3 & 3 & 3 & 3 & 3 & 3 & 3 & 3 & 3 & 3 & 3 & 3 & 3 \\
\hline SI & 0 & 0 & 0 & 0 & 0 & 0 & 0 & 3 & 3 & 1 & 1 & 1 & 1 & 1 & 1 & 1 & 1 \\
\hline SK & 0 & 0 & 0 & 0 & 0 & 0 & 0 & 0 & 0 & 0 & 0 & 0 & 0 & 0 & 0 & 0 & 0 \\
\hline
\end{tabular}

Notes: Categorization of anti-tax loss trafficking rules in the EU28 from 1998 to 2014. Category 0: No explicit anti-loss trafficking rule. Category 1: Denial of loss transfer after change in ownership and activity (cumulative requirement). Category 2: Denial of loss transfer after change in activity. Category 3: Denial of loss transfer after change in ownership. Category 4: Denial of loss transfer after change in ownership or activity (fulfillment of one criterion is sufficient). Retro-actively applicable rules are disregarded. Source: Bührle and Spengel (2020). 
Table 13: Sample composition, case studies

\begin{tabular}{|c|c|c|}
\hline Country & Number of observations & Percentage \\
\hline \multicolumn{3}{|c|}{ Case Study: Czech Republic } \\
\hline$C Z$ & 300 & 8.93 \\
\hline ES & 2,900 & 86.31 \\
\hline GR & 95 & 2.83 \\
\hline $\mathrm{HR}$ & 49 & 1.46 \\
\hline SK & 16 & 0.48 \\
\hline Total & 3,360 & 100 \\
\hline \multicolumn{3}{|c|}{ Case Study: Germany } \\
\hline AT & 740 & 1.2 \\
\hline $\mathrm{BE}$ & 2,331 & 3.78 \\
\hline$D E$ & 7,147 & 11.57 \\
\hline FR & 16,292 & 26.39 \\
\hline GB & 31,085 & 50.34 \\
\hline $\mathrm{IT}$ & 2,019 & 3.27 \\
\hline NL & 2,133 & 3.45 \\
\hline Total & 61,747 & 100 \\
\hline \multicolumn{3}{|c|}{ Case Study: Slovenia } \\
\hline $\mathrm{CY}$ & 64 & 16.58 \\
\hline GR & 16 & 4.15 \\
\hline HU & 118 & 30.57 \\
\hline PL & 134 & 34.72 \\
\hline SI & 48 & 12.44 \\
\hline SK & 6 & 1.55 \\
\hline Total & 386 & 100 \\
\hline
\end{tabular}


Table 14: Descriptive statistics, case studies

\begin{tabular}{|c|c|c|c|c|c|c|}
\hline Variable & Obs & Std. Dev. & Min & Mean & Median & Max \\
\hline \multicolumn{7}{|c|}{ Case Study: Czech Republic } \\
\hline \multicolumn{7}{|c|}{ Panel 1: Treatment group } \\
\hline VC funding & 300 & $3,590.58$ & 0.00 & 497.96 & 0.00 & $49,148.71$ \\
\hline Total Assets & 53 & 13.44 & 0.26 & 18.16 & 17.95 & 48.72 \\
\hline LCF amount (1 yr) & 53 & 1.53 & -9.19 & -0.57 & 0.00 & 0.00 \\
\hline Age & 300 & 5.46 & 0.00 & 10.74 & 11.00 & 24.00 \\
\hline \multicolumn{7}{|c|}{ Panel 2: Control group } \\
\hline VC funding & 3,060 & $2,386.13$ & 0.00 & 316.92 & 0.00 & $64,630.94$ \\
\hline Total Assets & 1,018 & 391.03 & 0.00 & 70.29 & 5.53 & $11,166.00$ \\
\hline LCF amount (1 yr) & 1,016 & 19.15 & -394.00 & -2.91 & 0.00 & 0.00 \\
\hline Age & 3,060 & 5.72 & 0.00 & 9.74 & 10.00 & 28.00 \\
\hline
\end{tabular}

Case Study: Germany

\begin{tabular}{|c|c|c|c|c|c|c|}
\hline \multicolumn{7}{|c|}{ Panel 1: Treatment group } \\
\hline VC funding & 7,147 & $5,738.53$ & 0.00 & 761.06 & 0.00 & $317,340.72$ \\
\hline Total Assets & 2,391 & $25,956.03$ & 0.00 & $1,089.10$ & 1.83 & $676,747.00$ \\
\hline LCF amount ( 1 yr) & 745 & 17.36 & -455.00 & -1.50 & 0.00 & 0.00 \\
\hline Age & 6,417 & 6.75 & 0.00 & 8.23 & 8.00 & 165.00 \\
\hline \multicolumn{7}{|c|}{ Panel 2: Control group } \\
\hline VC funding & 54,600 & $3,023.72$ & 0.00 & 468.74 & 0.00 & $309,271.72$ \\
\hline Total Assets & 18,948 & $12,400.63$ & 0.00 & 164.70 & 1.77 & $1,206,118.00$ \\
\hline LCF amount (1 yr) & 12,776 & 259.06 & $-19,660.24$ & -8.55 & 0.00 & 0.00 \\
\hline Age & 51,124 & 5.46 & 0.00 & 7.98 & 7.00 & 97.00 \\
\hline \multicolumn{7}{|c|}{ Case Study: Slovenia } \\
\hline \multicolumn{7}{|c|}{ Panel 1: Treatment group } \\
\hline VC funding & 48 & 921.84 & 0.00 & 240.51 & 0.00 & $4,284.42$ \\
\hline Total Assets & 5 & 0.11 & 0.94 & 1.06 & 1.02 & 1.19 \\
\hline LCF amount (1 yr) & 5 & 0.00 & 0.00 & 0.00 & 0.00 & 0.00 \\
\hline Age & 48 & 6.00 & 1.00 & 13.50 & 13.50 & 25.00 \\
\hline \multicolumn{7}{|c|}{ Panel 2: Control group } \\
\hline VC funding & 338 & $1,527.43$ & 0.00 & 223.65 & 0.00 & $21,654.12$ \\
\hline Total Assets & 51 & 141.14 & 0.51 & 96.63 & 25.10 & 483.54 \\
\hline LCF amount (1 yr) & 51 & 1.47 & -8.17 & -0.36 & 0.00 & 0.00 \\
\hline Age & 338 & 5.85 & 1.00 & 13.93 & 14.00 & 25.00 \\
\hline
\end{tabular}

Notes: Summary statistics for the variables, as defined in Table 11. Differentiated between case study and treatment (Panel 1) and control group (Panel 2). 


\begin{tabular}{|c|c|c|c|}
\hline & \multicolumn{3}{|c|}{$\begin{array}{c}\text { Event study } \\
\log (\mathrm{V} C \text { funding })\end{array}$} \\
\hline & CZ & $\mathrm{DE}$ & SI \\
\hline $\mathrm{t}-4$ & 2.048 & 0.037 & 1.903 \\
\hline $\mathrm{t}-3$ & 0.149 & 0.139 & 1.114 \\
\hline $\mathrm{t}-2$ & 0.230 & -0.075 & -0.134 \\
\hline $\mathrm{t}$ & $-1.326 * * *$ & -0.273 & $-1.331 * *$ \\
\hline$t+1$ & 0.084 & -0.243 & $-2.139 * *$ \\
\hline$t+2$ & $-1.783 * *$ & $-0.466^{* *}$ & 3.241 \\
\hline$t+3$ & -1.994 & -0.350 & 1.056 \\
\hline$t+4$ & $-2.030 *$ & $-0.549 * *$ & $1.398 *$ \\
\hline Escape clause & 0.155 & omitted & -0.678 \\
\hline LCF years & -0.038 & $0.019 * *$ & $-0.068 * *$ \\
\hline LCB years & omitted & -0.043 & omitted \\
\hline LCF limit & -0.059 & 0.065 & 1.650 \\
\hline CIT & -0.098 & 0.008 & $0.113^{* * *}$ \\
\hline$\Delta \mathrm{CIT}$ & 0.017 & -0.014 & -0.146 \\
\hline CGT & -5.034 & -0.129 & 0.995 \\
\hline DIT & 0.566 & 0.654 & -3.751 \\
\hline GDP per capita & -0.000 & 0.000 & -0.000 \\
\hline GDP growth & $0.198 * * *$ & 0.009 & -0.022 \\
\hline Unemployment & -0.044 & $-0.058 * *$ & -0.066 \\
\hline Inflation & $0.320 *$ & -0.047 & $0.211 * *$ \\
\hline EIF amount & -0.000 & -0.000 & -0.000 \\
\hline EIF number & 0.000 & -0.000 & 0.001 \\
\hline Lagged Public PE & -0.000 & $0.000 * *$ & - \\
\hline Firm FE & Yes & Yes & Yes \\
\hline Year FE & Yes & Yes & Yes \\
\hline \# Observations & 3,360 & 61,747 & 386 \\
\hline Adj. R-squared & 0.030 & 0.071 & 0.093 \\
\hline
\end{tabular}

Notes: Dependent variable: Firm-level VC funding volume. Results of the event study, difference between treatment and control group. " $\mathrm{t}$ ": time of change in legislation. " $\mathrm{t}-\mathrm{x}$ ": leads. " $\mathrm{t}+\mathrm{x}$ ": lags. Controls as indicated. Definition of variables: Table $11 . *, * *$, and $* * *$ indicate significance at the 10,5 , and $1 \%$ level. Standard errors: Clustered at country level. "Omitted": Variable was omitted from the regression due to multi-collinearity. 


\begin{tabular}{lccc}
\hline & \multicolumn{3}{c}{$\begin{array}{c}\text { I - Restriction category } \\
\log (\mathbf{V C} \text { funding) }\end{array}$} \\
\hline Treatment dummy & CZ & DE & SI \\
\hline Escape clause & -0.731 & $-0.524^{* * *}$ & -0.479 \\
LCF years & 0.008 & -0.159 & -0.629 \\
LCB years & -0.012 & $0.020^{* * *}$ & -0.011 \\
LCF limit & omitted & -0.035 & omitted \\
CIT & -0.418 & 0.075 & $1.286^{* *}$ \\
$\Delta$ CIT & -0.017 & 0.006 & $0.070^{*}$ \\
CGT & -0.032 & -0.016 & -0.136 \\
DIT & -4.376 & -0.096 & 0.977 \\
GDP per capita & -0.649 & 0.662 & -3.830 \\
GDP growth & 0.000 & 0.000 & $-0.000^{*}$ \\
Unemployment & 0.069 & -0.002 & 0.004 \\
Inflation & -0.005 & $-0.054^{* *}$ & -0.058 \\
EIF amount & 0.179 & -0.064 & $0.164^{* *}$ \\
EIF number & 0.001 & 0.000 & -0.002 \\
Lagged Public PE & 0.000 & -0.000 & $0.001^{* *}$ \\
\hline Firm FE & -0.000 & $0.000^{* *}$ & - \\
Year FE & Yes & Yes & Yes \\
\hline \# Observations & Yes & Yes & Yes \\
Adj. R-squared & 3,360 & 61,747 & 386 \\
\hline Nos: Resurs & 0.027 & 0.071 & 0.075 \\
\hline
\end{tabular}

Notes: Results linear DiD regressions of treatment dummy on the logarithm of VC funding volume received. Treatment dummy equals 1 in the year of change in legislation and all following years, and zero otherwise. Controls as indicated. Definition of variables: Table 11 (appendix). *,**, and *** indicate significance at the 10, 5, and $1 \%$ level. Standard errors: Clustered at country level. "Omitted": Variable was omitted from the regression due to multi-collinearity. 
Table 17: Results event study, combined analysis

\begin{tabular}{|c|c|c|c|c|}
\hline & & $\begin{array}{r}E \\
\log ( \\
\end{array}$ & $\begin{array}{l}\text { dy } \\
\text { ding) }\end{array}$ & \\
\hline & 1 & 2 & 3 & 4 \\
\hline $\mathrm{t}-4$ & $-0.274 * * *$ & $-0.145^{*}$ & -0.134 & -0.131 \\
\hline $\mathrm{t}-3$ & -0.114 & -0.095 & -0.101 & -0.099 \\
\hline $\mathrm{t}-2$ & -0.099 & -0.127 & -0.145 & -0.143 \\
\hline $\mathrm{t}$ & $-0.345^{* *}$ & $-0.264^{*}$ & -0.311 & -0.318 \\
\hline$t+1$ & $-0.472 * * *$ & $-0.336^{*}$ & $-0.469 * *$ & $-0.471 * *$ \\
\hline$t+2$ & $-0.444 * *$ & $-0.315^{*}$ & $-0.549 * * *$ & $-0.545 * * *$ \\
\hline$t+3$ & $-0.467 * *$ & -0.291 & $-0.602 * * *$ & $-0.595 * * *$ \\
\hline$t+4$ & $-0.497 * * *$ & $-0.291 *$ & $-0.568 * * *$ & $-0.559 * * *$ \\
\hline Escape clause & & & 0.229 & 0.226 \\
\hline LCF years & & & 0.004 & 0.004 \\
\hline LCB years & & & $0.110 *$ & $0.110^{*}$ \\
\hline LCF limit & & & $0.303 * *$ & $0.316 * *$ \\
\hline CIT & & & -0.016 & -0.018 \\
\hline$\Delta \mathrm{CIT}$ & & & 0.006 & 0.004 \\
\hline CGT & & & -0.717 & -0.794 \\
\hline DIT & & & -0.142 & -0.138 \\
\hline GDP per capita & & & 0.000 & 0.000 \\
\hline GDP growth & & & 0.020 & 0.020 \\
\hline Unemployment & & & $-0.037 *$ & $-0.038 *$ \\
\hline Inflation & & & $-0.069 *$ & $-0.068 *$ \\
\hline EIF amount & & & -0.000 & -0.000 \\
\hline EIF number & & & 0.000 & 0.000 \\
\hline Lagged Public PE & & & 0.000 & 0.000 \\
\hline Lagged total assets & & & & -0.000 \\
\hline Age & & & & $-0.062 * * *$ \\
\hline LCF amount ( $1 \mathrm{yr}$ ) & & & & 0.000 \\
\hline Firm FE & Yes & Yes & Yes & Yes \\
\hline Year FE & & Yes & Yes & Yes \\
\hline \# Observations & 17,331 & 17,331 & 17,331 & 17,331 \\
\hline Adj. R-squared & 0.002 & 0.008 & 0.009 & 0.010 \\
\hline
\end{tabular}

Notes: Results of the event study of treatment intensity on the logarithm of VC funding volume received " $\mathrm{t}$ ": time of change in legislation. "t-x": leads. "t+x": lags. Controls as indicated. Definition of variables: Table 11. *,**, and $* * *$ indicate significance at the 10,5 , and $1 \%$ level. Standard errors: Clustered at country level. 
Table 18: Generalized DiD results, restriction category, VC funding volume percentiles

\begin{tabular}{|c|c|c|c|c|}
\hline & Below $25 \%$ & $25 \%$ to $50 \%$ & $50 \%$ to $75 \%$ & Above $75 \%$ \\
\hline & \multicolumn{4}{|c|}{$\log (\mathrm{VC}$ funding $)$} \\
\hline & $\mathrm{I}-4$ & $\mathrm{I}-4$ & $\mathrm{I}-4$ & $\mathrm{I}-4$ \\
\hline Restriction category & $-0.121 *$ & $-1.565 * * *$ & -0.326 & $-1.000 * *$ \\
\hline Escape clause & $0.238 * *$ & $-0.833 * *$ & $1.137^{*}$ & -0.135 \\
\hline LCF years & $0.009 * *$ & 0.020 & $-0.092 * *$ & 0.033 \\
\hline LCB years & $-0.094 * * *$ & $0.787 * * *$ & $0.279 * *$ & 0.252 \\
\hline LCF limit & -0.063 & $1.291 * * *$ & $1.866 * * *$ & 0.167 \\
\hline CIT & $-0.041 *$ & 0.072 & -0.127 & $0.156^{*}$ \\
\hline$\Delta \mathrm{CIT}$ & 0.010 & $-0.094 * * *$ & 0.036 & $-0.107 * * *$ \\
\hline CGT & 0.867 & $-5.802 * * *$ & -2.553 & -4.189 \\
\hline DIT & 0.303 & -0.885 & -1.505 & 0.655 \\
\hline GDP per capita & 0.000 & 0.000 & -0.000 & $0.000 *$ \\
\hline GDP growth & -0.007 & -0.029 & -0.072 & 0.140 \\
\hline Unemployment & -0.018 & $-0.129 *$ & $-0.201 * *$ & 0.054 \\
\hline Inflation & $-0.037 *$ & -0.166 & -0.289 & 0.021 \\
\hline EIF amount & $-0.000 *$ & $0.001 * *$ & -0.000 & -0.001 \\
\hline EIF number & $0.000 * *$ & -0.000 & 0.000 & 0.000 \\
\hline Lagged Public PE & -0.000 & 0.000 & -0.000 & 0.000 \\
\hline Lagged total assets & $-0.000 * *$ & 0.000 & -0.000 & -0.000 \\
\hline Age & $-0.049 * * *$ & $-0.053 * * *$ & -0.048 & $-0.289 * *$ \\
\hline LCF amount (1 yr) & -0.000 & $-0.004 * * *$ & $0.001 *$ & 0.000 \\
\hline Country FE & Yes & Yes & Yes & Yes \\
\hline Year FE & & Yes & Yes & Yes \\
\hline \# Observations & 10,074 & 2,645 & 2,634 & 2,037 \\
\hline Adj. R-squared & 0.010 & 0.017 & 0.016 & 0.040 \\
\hline
\end{tabular}

Notes: Results linear generalized DiD regressions of restriction category (see Table 1) on the VC funding volume received. Categories range from 0 to 4 , a higher restriction category implies more restrictive anti-tax loss trafficking rules. Controls as indicated. Definition of variables: Table 11 (appendix). Differentiation depending on percentile in distribution of total VC funding volume of companies as indicated. *, **, and *** indicate significance at the 10,5, and $1 \%$ level. Standard errors: Clustered at country level. 
Table 19: Generalized DiD results, restriction category, age

\begin{tabular}{|c|c|c|c|c|}
\hline & 0 to 5 years & 5 to 10 years & 10 to 15 years & Above 15 years \\
\hline & \multicolumn{4}{|c|}{$\log (\mathrm{VC}$ funding $)$} \\
\hline & $\mathrm{I}-4$ & $\mathrm{I}-4$ & $\mathrm{I}-4$ & $\mathrm{I}-4$ \\
\hline Restriction category & $-0.791 *$ & -0.030 & $-0.910 * * *$ & -0.014 \\
\hline Escape clause & 0.829 & $0.531 *$ & -0.054 & 0.115 \\
\hline LCF years & $-0.056 *$ & $0.040 * *$ & $0.035 * * *$ & 0.032 \\
\hline LCB years & 0.027 & $0.189 * * *$ & $0.108 * *$ & -0.120 \\
\hline LCF limit & 0.370 & $0.602 * * *$ & 0.003 & -0.071 \\
\hline CIT & $-0.108 *$ & 0.042 & -0.026 & $-0.049 *$ \\
\hline$\Delta \mathrm{CIT}$ & -0.019 & $-0.057 * *$ & 0.005 & 0.006 \\
\hline CGT & -1.355 & 0.932 & -1.378 & -0.489 \\
\hline DIT & -0.329 & 0.255 & 1.526 & 1.160 \\
\hline GDP per capita & 0.000 & $0.000 * *$ & 0.000 & -0.000 \\
\hline GDP growth & -0.117 & 0.030 & $0.093 * * *$ & 0.030 \\
\hline Unemployment & $-0.147 * * *$ & $0.065 * * *$ & $-0.051 *$ & $-0.094 * *$ \\
\hline Inflation & -0.037 & -0.018 & $-0.153 * *$ & -0.072 \\
\hline EIF amount & -0.001 & 0.000 & $-0.001 * * *$ & $-0.001 * *$ \\
\hline EIF number & $0.000 * *$ & -0.000 & $0.000 * * *$ & $0.000 * * *$ \\
\hline Lagged Public PE & -0.000 & 0.000 & $-0.000 * *$ & -0.000 \\
\hline Lagged total assets & $-0.000 * *$ & 0.000 & $-0.000 * * *$ & -0.000 \\
\hline Age & $-0.252 * * *$ & $-0.261 * * *$ & 0.014 & -0.015 \\
\hline LCF amount (1 yr) & -0.000 & 0.000 & 0.000 & 0.000 \\
\hline Country FE & Yes & Yes & Yes & Yes \\
\hline Year FE & Yes & Yes & Yes & Yes \\
\hline \# Observations & 4,541 & 7,100 & 5,027 & 3,391 \\
\hline Adj. R-squared & 0.009 & 0.014 & 0.009 & 0.000 \\
\hline
\end{tabular}

Notes: Results linear generalized DiD regressions of restriction category (see Table 1) on the logarithm of VC funding volume received. Categories range from 0 to 4 , a higher restriction category implies more restrictive antitax loss trafficking rules. Controls as indicated. Definition of variables: Table 11 (appendix). Differentiation depending on age of companies as indicated. $*{ }^{* *}$, and $* * *$ indicate significance at the 10,5 , and $1 \%$ level. Standard errors: Clustered at country level. 


\begin{tabular}{ll}
\hline NACE Code (Rev 2) & Industry Classification \\
\hline $21 \mathrm{xx}$ & Pharmaceutical \\
$26 \mathrm{xx}$ & ICT Manufacturing \\
$20 \mathrm{xx}$ & Chemicals \\
$27 \mathrm{xx}-30 \mathrm{xx}$ & Electrical equipment, machinery, and equipment n.e.c... \\
$59 \mathrm{xx}-63 \mathrm{xx}$ & Video production, programming, information services... \\
$72 \mathrm{xx}$ & Scientific R\&D \\
\hline
\end{tabular}

Notes: Industry sectors classified as "high-tech" based on the company's four-digit NACE code. All industries not classified as "high-tech" are considered "low-tech".

Table 21: Generalized DiD results, restriction category, low-vs. high-tech

\begin{tabular}{lcc}
\hline & Low-tech companies & $\begin{array}{c}\text { High-tech companies } \\
\log (\mathbf{V C} \text { funding) }\end{array}$ \\
\hline Restriction category & $\mathrm{I}-4$ & $\mathrm{I}-4$ \\
\hline Escape clause & $-0.272^{*}$ & $-0.510^{* * *}$ \\
LCF years & -0.020 & 0.149 \\
LCB years & 0.018 & -0.016 \\
LCF limit & 0.050 & $0.241^{* * *}$ \\
CIT & $0.342^{* *}$ & $0.424^{* *}$ \\
$\Delta$ CIT & -0.048 & 0.021 \\
CGT & 0.027 & $-0.054^{* *}$ \\
DIT & $-1.365^{* *}$ & -1.371 \\
GDP per capita & 1.155 & $-2.065^{* *}$ \\
GDP growth & 0.000 & -0.000 \\
Unemployment & 0.004 & 0.014 \\
Inflation & -0.030 & $-0.075^{* * *}$ \\
EIF amount & -0.045 & $-0.116^{* *}$ \\
EIF number & $-0.000^{*}$ & 0.000 \\
Lagged Public PE & $0.000^{* *}$ & -0.000 \\
\hline Lagged total assets & 0.000 & -0.000 \\
Age & $-0.000^{* *}$ & -0.000 \\
LCF amount $(1$ yr) & $-0.055^{* * *}$ & $-0.064^{* * *}$ \\
\hline Country FE & -0.000 & $0.000^{*}$ \\
Year FE & Yes & Yes \\
\hline \# Observations & Yes & Yes \\
Adj. R-squared & 9,358 & 7,895 \\
\hline Notes Re & 0.008 & 0.014 \\
\hline
\end{tabular}

Notes: Results linear generalized DiD regressions of restriction category (see Table 1) on the logarithm of VC funding volume received. Categories range from 0 to 4 , a higher restriction category implies more restrictive antitax loss trafficking rules. Controls as indicated. Definition of variables: Table 11 (appendix). Differentiation depending on industry of companies as indicated. *,**, and *** indicate significance at the 10,5 , and $1 \%$ level. Standard errors: Clustered at country level. 
A2 VICO 4.0 Database, Construction of the Sample, and Potential Sample Selection Bias

The European Commission's RISIS initiative provides the VICO 4.0 database. The database has been used in several studies in the management and finance area for research questions investigating the VC industry (e.g., Bertoni, Croce, \& Guerini, 2015; Croce, D'Adda, \& Ughetto, 2015; Croce, Martí, \& Murtinu, 2013; Grilli \& Murtinu, 2014; Guerini \& Quas, 2016).

\section{Table 22: Sample construction}

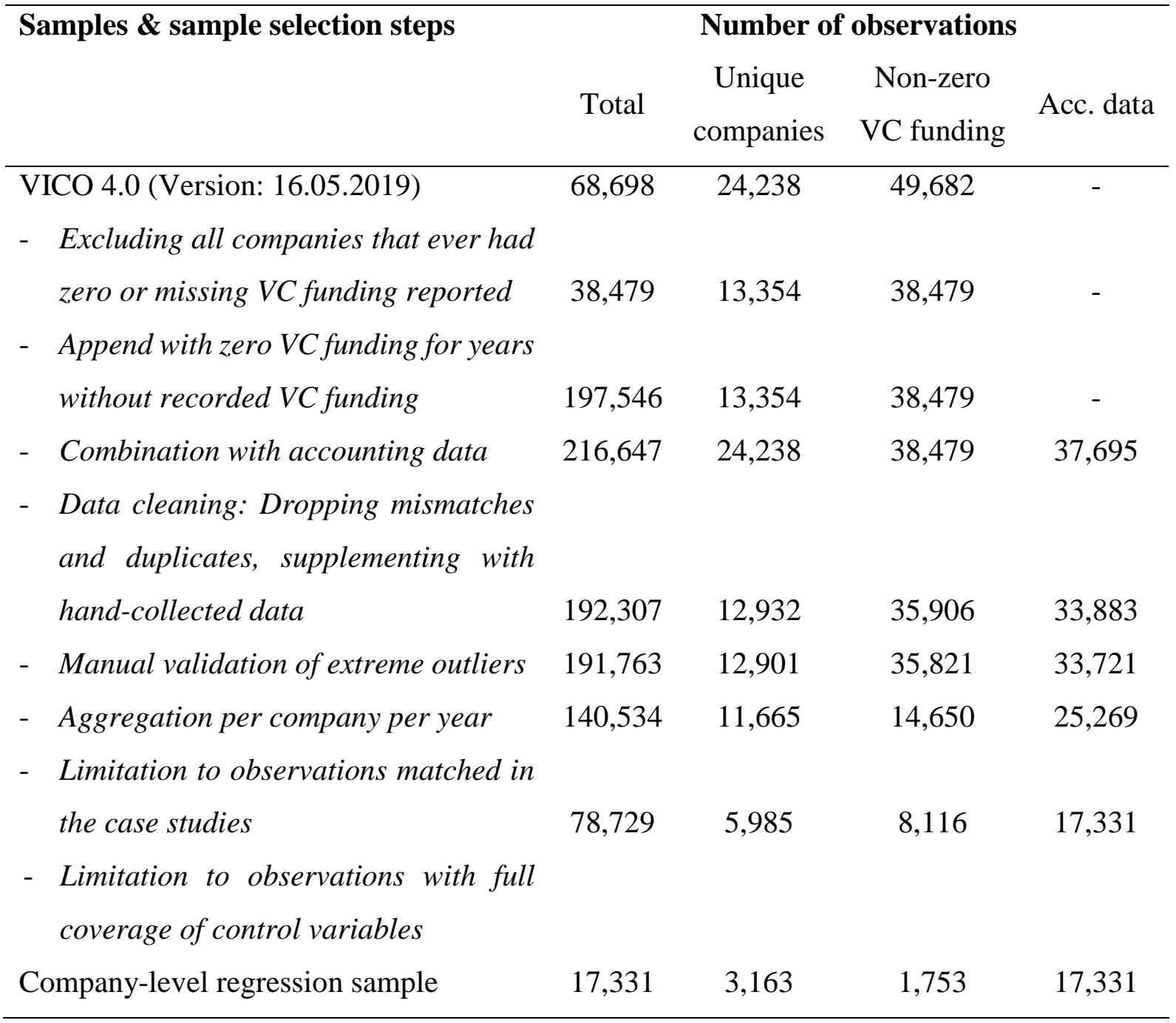

Notes: Procedure of sample construction. Report of resulting numbers of observations, differentiated by total number of observations, number of unique companies in the dataset, count of observations reporting non-zero VC funding, and number of observations with accounting data (total assets and profits and losses before taxes) available.

It contains data on VC funding from Thompson One Private Equity (over 70\%), Zephyr (around 25\%), and Crunchbase (less than 5\%), ${ }^{35}$ covering companies founded since 1988 that were funded via VC or angel investment at least once since 1998 in the EU28 until 2015. Data is available on a company- (name, country, industry codes, age, balance sheet data), funding -

\footnotetext{
${ }^{35}$ As Thomson One Private Equity and Crunchbase record VC funding in dollars, the equity raised has been converted into thousand euros at exchange rates at the day of the funding.
} 
(date, volume, number of rounds), and investor-level (name, country, type, industry codes, age). I winsorize VC funding at the 1 and 99 percent level. The last year shows a sudden decrease in observations, which is attributable to limitations in the data collection process (at the time of the data set's construction, not all information was readily available for the last year). Therefore, I drop 2015 from the sample.

Some of the zero VC funding observations report a known or unknown but existing investor. Therefore, it is impossible to differentiate between "true" zero investment, where no funding took place, and investments with missing, but positive, funding volumes. I assume that the sample is complete in the sense that if I include a company, all funding rounds in the observation period are covered. This assumption does not require all VC funding events to be covered; it only demands the ones that I included to be complete. Therefore, I exclude all zero and missing company-year observations and all companies that ever had a zero or missing funding volume reported. Based on my assumption, I extend the data sample and add observations for years with no recorded VC investment with zeros inserted for VC funding.

The accounting data that supplements the dataset originates from BvD's Orbis database. First, I add Orbis data already provided within the VICO 4.0 framework, which covers the years 2005 to 2014. For the other years, I add Orbis data supplied by the database available at the University of Mannheim, based on the BvD IDs included in the VICO 4.0 database. I do not find matches in the accounting data for the entire sample. As a result, the observations pre-2006 account for less than $2 \%$ of all observations. ${ }^{36}$ This discrepancy is caused by missing BvD IDs, the available BvD IDs not having an equivalent in the Orbis database, or, although the IDs match, simply no accounting information being available. Table 23 depicts the distribution of observations amongst countries and years in the final regression sample.

The constraint to full accounting information introduces a bias in the sample: Often, small companies are not required to publish financial statements and thus not covered in Orbis. The thresholds for mandatory disclosure vary across countries in the size and type of measure (most commonly used are revenue, assets, or number of employees). I limit the constraint to the items with the best coverage within the sample: Profits and losses and total assets. Nevertheless, I tend to observe companies that are, compared to the total population of VC-backed companies,

\footnotetext{
${ }^{36}$ I repeat the name-matching between VICO 4.0 and Orbis for all companies that received funding before 2006. I am not able to extend the data. While a significant amount of the companies can be matched to an Orbis entry, the accounting coverage is severely lacking. However, excluding the period before 2006 does not greatly influence the estimates in chapter 5.3. The results for the analysis limited to $2006-2014$ are not reported in this paper, but are available upon request from the author.
} 
relatively large (albeit still small compared to the total population of firms in Orbis). The case studies rely on a matching approach that includes missing values and does not enforce this data restriction. However, the combined analysis has to be evaluated in light of the accounting datainduced sample selection bias.

Table 23: Distribution of observations per country \& per year

\begin{tabular}{lrr|l|rrr}
\hline Country & \# Obs. & Percentage & & Year & \# Obs. & Percent \\
\hline AT & 89 & 0.51 & & 1999 & 50 & 0.29 \\
BE & 755 & 4.36 & & 2000 & 57 & 0.33 \\
BG & 6 & 0.03 & & 2001 & 55 & 0.32 \\
CZ & 99 & 0.57 & 2002 & 48 & 0.28 \\
DE & 751 & 4.33 & & 2003 & 46 & 0.27 \\
ES & 2,594 & 14.97 & 2004 & 49 & 0.28 \\
FR & 5,907 & 34.08 & 2005 & 42 & 0.24 \\
GB & 5,293 & 30.54 & & 2006 & 1,589 & 9.17 \\
GR & 38 & 0.22 & & 2007 & 1,746 & 10.07 \\
HR & 57 & 0.33 & & 2008 & 1,857 & 10.71 \\
HU & 262 & 1.51 & & 1,933 & 11.15 \\
IT & 717 & 4.14 & & 2009 & 1,987 & 11.47 \\
LT & 71 & 0.41 & & 2010 & 1,995 & 11.51 \\
LV & 74 & 0.43 & & 2011 & 2,024 & 11.68 \\
NL & 127 & 0.73 & 2012 & 2,002 & 11.55 \\
PL & 190 & 1.1 & 2013 & 1,851 & 10.68 \\
PT & 185 & 1.07 & 2014 & & \\
RO & 66 & 0.38 & & & & \\
SI & 9 & 0.05 & & & & \\
SK & 41 & 0.24 & & & & \\
\hline Total & 17,731 & 100 & & Total & 17,331 & 100 \\
\hline
\end{tabular}

Notes: Geographic and temporal distribution of observations in the full sample (limited to observations with complete information on aggregated VC funding per company year, country- and company-level control variables). Some of the smaller EU28 Member States included in the original VICO 4.0 data set are excluded due to missing supplementary data in the company-year observations concerned. The sudden increase in observations from 2005 onwards results from incomplete coverage of accounting information in the data pre-2006. 


\section{A3 Calculation Example for Loss Carryforwards (4 years)}

Based on Bernasconi, Marenzi, and Pagani's (2005) method, past losses (before taxes) are offset against subsequent profits. I only consider previous losses if there is no tax liability in t-1; otherwise, the value of the LCF in $t$ is set to zero. This approach assumes that positive tax payments in t-1 indicate that all LCFs have been used, and no loss can be carried over from t1. As a result, I disregard restrictions regarding the maximum percentage or amount of LCFs that can be set off in a year (so-called minimum taxation). I set LCF (4 years) to missing in case the information on tax payments in $\mathrm{t}-1$ is not available (see Table 24 for an example).

Table 24: Calculation example LCF (4 years)

\begin{tabular}{lccccc}
\hline & $\mathbf{t}-\mathbf{4}$ & $\mathbf{t}-\mathbf{3}$ & $\mathbf{t}-\mathbf{2}$ & $\mathbf{t}-\mathbf{1}$ & $\mathbf{t}$ \\
\hline P\&L & 100 & 200 & -300 & 150 & \\
Taxation & 20 & 50 & 0 & 0 & \\
LCF & & 0 & 0 & -300 & LCF (4 years) $=\mathbf{- 1 5 0}$ \\
\hline \hline P\&L & 100 & 200 & -300 & 150 & \\
Taxation & 20 & 50 & 0 & 50 & \\
LCF & & 0 & 0 & -300 & LCF (4 years) $=$ 0 \\
\hline P\&L & 100 & -100 & -300 & 150 & \\
Taxation & 20 & 50 & 0 & 0 & \\
LCF & & 0 & 0 & -300 & LCF (4 years) $=$.
\end{tabular}

Notes: Three examples for the calculation of the four-year based LCF measure. Periods considered are four years previous to t. Past losses are netted against subsequent profits. The value of the LCF is set to zero in case of positive tax payment in $\mathrm{t}-1$, and set to missing in case of missing tax payment in $\mathrm{t}-1$. 


\section{A4 Additional Country Case Studies}

In the following sub-sections, I provide the results for the remaining country case studies that I do not include in the main analysis in section 4 . From the full set of legislation changes available for analysis (see Table 12), the changes in the Netherlands and Portugal are missing. For these countries, it was not possible to construct control groups that satisfied the common trends assumption.

\section{A4.1 Greece}

Greece introduced its first tax loss transfer restrictions in 2014. Loss carryforwards were denied after a change in ownership above one-third of the company's shares. An exemption was made when the taxpayer could provide evidence that the change in the ownership structure had economic reasons; in other words, that it was not purely tax-motivated.

\section{Figure 11: Results case study, Greece}

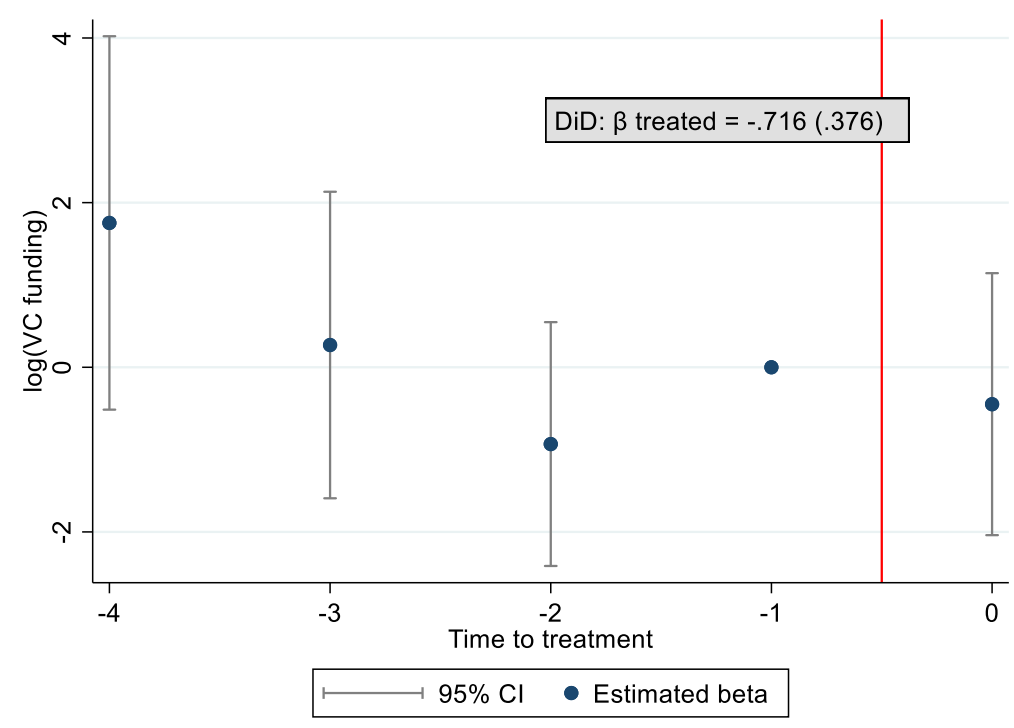

Notes: Event: Greece, introduction ownership-based regime in 2014. Dependent variable: Firm-level VC funding volume. Main graph: Results of the event study, difference between treatment and control group. Time dummies: " 0 ": time of change in legislation. "-t": leads. " $t$ ": lags. 95\% confidence intervals. Grey box: Results of the panel analysis; standard error in parenthesis. *, **, and *** indicate significance at the 10, 5, and 1\% level. Sample composition: Table 25. Descriptive statistics: Table 26. Event study results: Table 27. Panel regression results: Table 28.

As the sample ends in 2014, no post periods are available for the change in Greek legislation (Figure 11). The event study and the panel analysis indicate a negative effect, but the coefficient is statistically significant in neither case. Therefore, no clear conclusion can be drawn in this case based on the data available in this study. 


\section{A4.2 Croatia}

In 2010, Croatia introduced a cumulative regime. After a substantial change in ownership of more than $50 \%$, loss carryforwards could be dismissed. This was the case if the company did not perform any business activity in the two years preceding the change in ownership or when the company's business activity was changed significantly in the two years following the change in ownership. A rehabilitation exception applied.

\section{Figure 12: Results case study, Croatia}

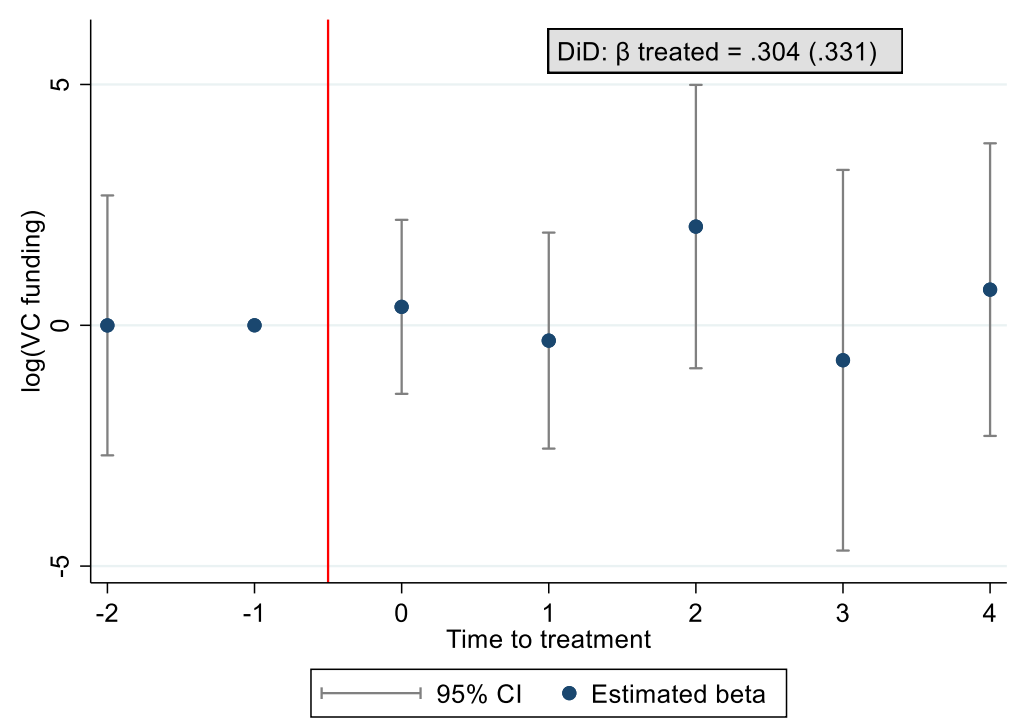

Notes: Event: Croatia, introduction cumulative regime in 2010. Dependent variable: Firm-level VC funding volume. Main graph: Results of the event study, difference between treatment and control group. Time dummies: " 0 ": time of change in legislation. "-t": leads. "t": lags. 95\% confidence intervals. Grey box: Results of the panel analysis; standard error in parenthesis. *,**, and *** indicate significance at the 10,5 , and $1 \%$ level. Sample composition: Table 25. Descriptive statistics: Table 26. Event study results: Table 27. Panel regression results: Table 28.

Figure 12 depicts the results for the change in legislation in Croatia. ${ }^{37}$ Neither the event study nor the panel analysis suggest any significant effects of the restrictions on VC funding. This is in line with expectations, as the type of regulation introduced in Croatia is far less restrictive than the regimes implemented in, e.g., the Czech Republic (Figure 4) or Germany (Figure 5). As long as start-ups retained their business activities, they did not risk losing accumulated loss carryforwards, irrespective of ownership changes.

\section{A4.3 Hungary}

Hungary already had an ownership-based regime in place until 2000. Loss carryforwards were denied if more than $50 \%$ of the shares changed ownership. The restrictions were abolished in 2001 until a cumulative regime was introduced in 2012. The threshold was again set at $50 \%$.

\footnotetext{
${ }^{37}$ In the case of Croatia, only two pre-periods are available for the regression. The data on government-funded PE provided by InvestEurope does not include Croatia until 2007. Nevertheless, companies have been matched on the matching parameters in the three periods preceding the change in legislation.
} 
Still, an activity clause now accompanied the ownership-criterion: The rules only applied if the company did not maintain its activity and generated revenues in the two years following the acquisition. There were no additional exemptions codified in tax law.

\section{Figure 13: Results case study, Hungary (2001)}

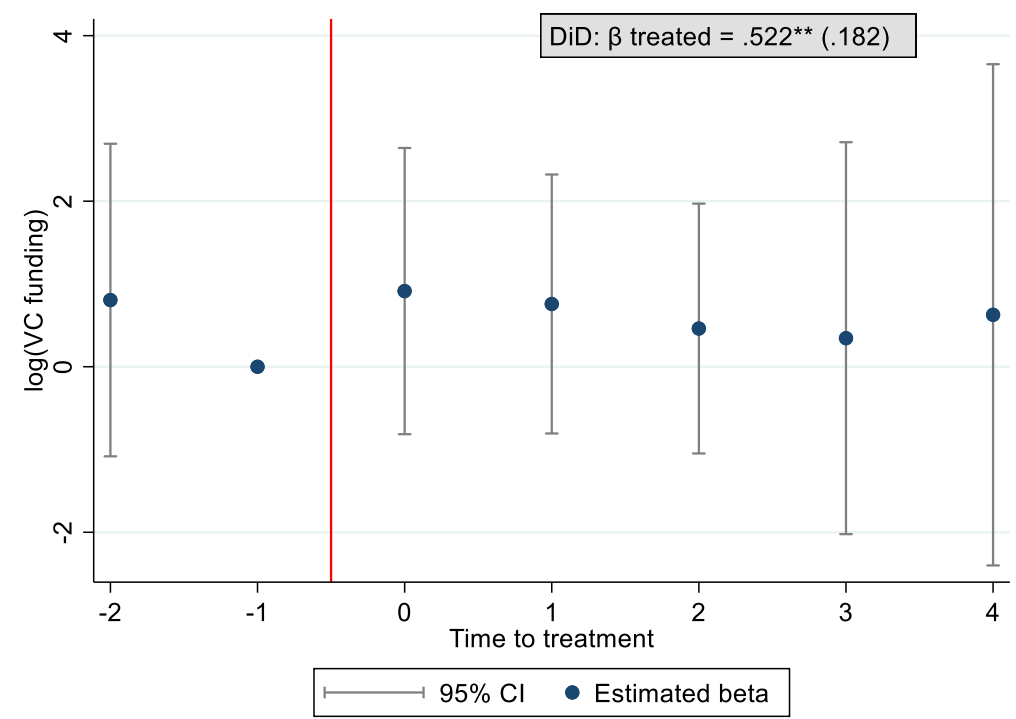

Notes: Event: Hungary, abolishment of ownership-based regime in 2001. Dependent variable: Firm-level VC funding volume. Main graph: Results of the event study, difference between treatment and control group. Time dummies: "0": time of change in legislation. "-t": leads. "t": lags. 95\% confidence intervals. Grey box: Results of the panel analysis; standard error in parenthesis. *, **, and *** indicate significance at the 10, 5, and 1\% level. Sample composition: Table 25. Descriptive statistics: Table 26. Event study results: Table 27. Panel regression results: Table 28.

Figure 14: Results case study, Hungary (2012)

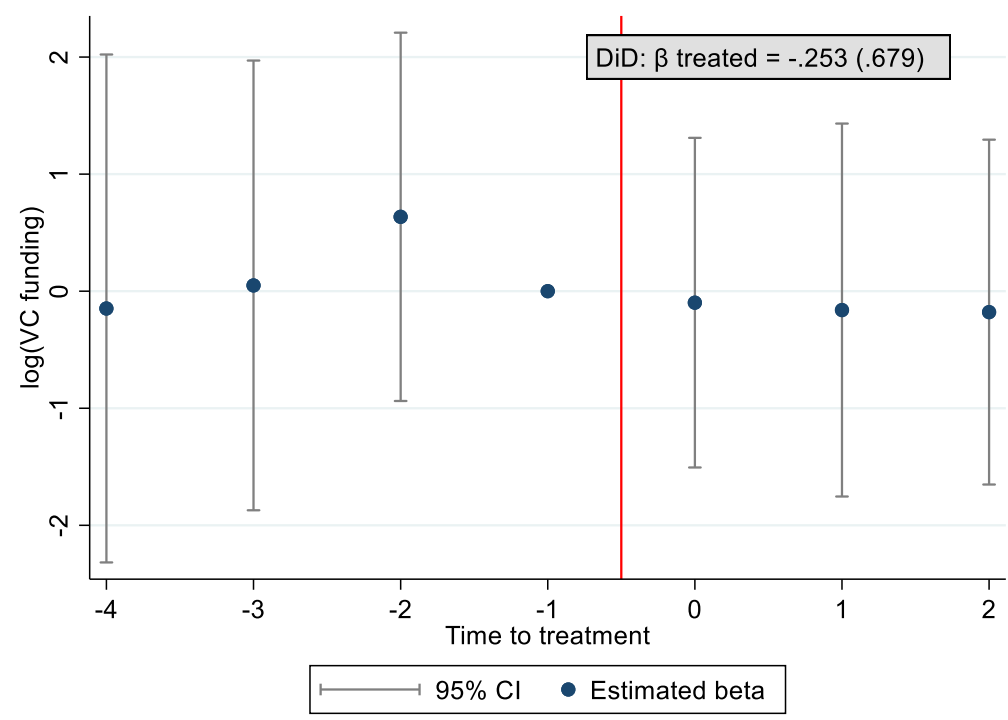

Notes: Event: Hugary, introduction cumulative regime in 2012. Dependent variable: Firm-level VC funding volume. Main graph: Results of the event study, difference between treatment and control group. Time dummies: " 0 ": time of change in legislation. "-t": leads. " $t$ ": lags. 95\% confidence intervals. Grey box: Results of the panel analysis; standard error in parenthesis. *,**, and *** indicate significance at the 10,5 , and $1 \%$ level. Sample composition: Table 25. Descriptive statistics: Table 26. Event study results: Table 27. Panel regression results: Table 28. 
Figure 13 and Figure 14 depict the results for the change in legislation $2001^{38}$ and 2012, respectively. The sample spans 1999 to 2014. Consequently, for the abolishment of the ownershipbased regime 2001, only two pre-periods are available, and the cumulative regime's introduction in 2012 only two post-periods. For both event studies, the coefficients suggest a positive effect of the abolishment and a negative impact of introducing the restrictions, none are statistically different. However, in line with my hypotheses the panel results indicate an increase in $\mathrm{VC}$ funding in reaction to the abolishment of the ownership-based restrictions.

\section{A4.4 Lithuania}

In 2002, the Lithuanian legislators introduced a cumulative anti-tax loss trafficking regime. Following an ownership change of more than two-thirds, loss carryforwards were forfeited if the corporation generated less than $85 \%$ of the income with the same activity that resulted in the losses. The tax law did not specify additional exemptions from the restriction.

\section{Figure 15: Results case study, Lithuania}

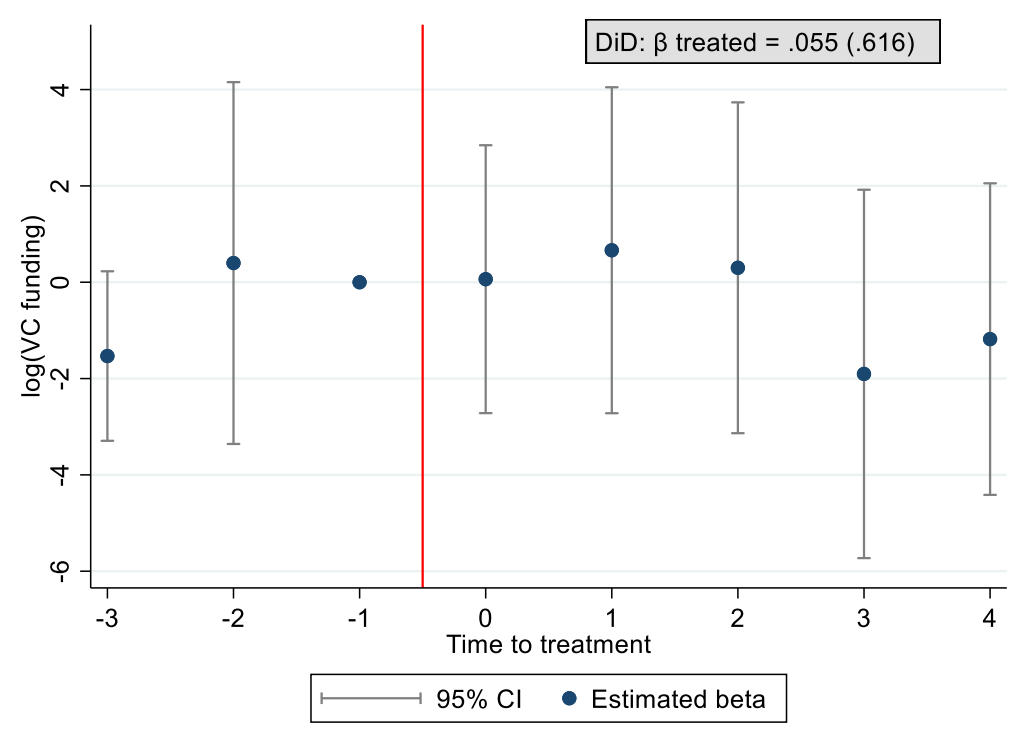

Notes: Event: Lithuania, introduction cumulative regime in 2002. Dependent variable: Firm-level VC funding volume. Main graph: Results of the event study, difference between treatment and control group. Time dummies: " 0 ": time of change in legislation. "-t": leads. " $t$ ": lags. 95\% confidence intervals. Grey box: Results of the panel analysis; standard error in parenthesis. *, **, and *** indicate significance at the 10, 5, and $1 \%$ level. Sample composition: Table 25. Descriptive statistics: Table 26. Event study results: Table 27. Panel regression results: Table 28.

\footnotetext{
${ }^{38}$ In deviation from the regression equation stated in formula (1) and (2), in the case of Hungary (2001) government-funded PE is not included as a control. The data provided by InvestEurope does not include Hungary until 2007. However, the controls for funding programs from the EIF are available.
} 
Figure 15 summarizes the estimates for the introduction of a cumulative regime in Lithuania. ${ }^{39}$ As the sample starts in 1999 , for the change in 2002, only three pre-periods are available. Similarly to the introduction of cumulative restrictions in Croatia and Hungary, there is no indication of VC funding impairment due to the restrictions.

\footnotetext{
${ }^{39}$ In deviation from the regression equation stated in formula (1) and (2), in the case of Lithuania governmentfunded PE is not included as a control. The data provided by InvestEurope does not include Lithuania until 2007. However, the controls for funding programs from the EIF are available.
} 
A4.5 Supplementary Tables (Additional Case Studies)

Table 25: Sample composition, case studies (appendix)

\begin{tabular}{|c|c|c|}
\hline Country & Number of observations & Percentage \\
\hline \multicolumn{3}{|c|}{ Case study: Greece } \\
\hline $\mathrm{CZ}$ & 276 & 10.45 \\
\hline ES & 1,722 & 65.23 \\
\hline$G R$ & 188 & 7.12 \\
\hline PT & 396 & 15 \\
\hline SI & 38 & 1.44 \\
\hline SK & 20 & 0.76 \\
\hline Total & 2,640 & 100 \\
\hline \multicolumn{3}{|c|}{ Case study: Croatia } \\
\hline BG & 7 & 1.04 \\
\hline $\mathrm{CZ}$ & 109 & 16.22 \\
\hline$H R$ & 83 & 12.35 \\
\hline LT & 50 & 7.44 \\
\hline LV & 55 & 8.18 \\
\hline PL & 291 & 43.3 \\
\hline RO & 69 & 10.27 \\
\hline SK & 8 & 1.19 \\
\hline Total & 672 & 100 \\
\hline \multicolumn{3}{|c|}{ Case study: Hungary (2001) } \\
\hline$\overline{\mathrm{HR}}$ & 118 & 7.97 \\
\hline$H U$ & 474 & 32.03 \\
\hline LV & 64 & 4.32 \\
\hline PL & 601 & 40.61 \\
\hline RO & 141 & 9.53 \\
\hline SI & 48 & 3.24 \\
\hline SK & 34 & 2.3 \\
\hline Total & 1,480 & 100 \\
\hline \multicolumn{3}{|c|}{ Case study: Hungary (2012) } \\
\hline $\mathrm{CZ}$ & 326 & 12.78 \\
\hline$H U$ & 868 & 34.03 \\
\hline LT & 81 & 3.18 \\
\hline LV & 149 & 5.84 \\
\hline PL & 797 & 31.24 \\
\hline RO & 170 & 6.66 \\
\hline SI & 52 & 2.04 \\
\hline SK & 108 & 4.23 \\
\hline Total & 2,551 & 100 \\
\hline \multicolumn{3}{|c|}{ Case study: Lithuania } \\
\hline BG & 16 & 2.73 \\
\hline$L T$ & 80 & 13.65 \\
\hline LV & 48 & 8.19 \\
\hline PL & 288 & 49.15 \\
\hline RO & 120 & 20.48 \\
\hline SK & 34 & 5.8 \\
\hline Total & 586 & 100 \\
\hline
\end{tabular}


Table 26: Descriptive statistics, case studies (appendix)

\begin{tabular}{|c|c|c|c|c|c|c|}
\hline Variable & Obs & Std. Dev. & Min & Mean & Median & Max \\
\hline \multicolumn{7}{|c|}{ Case Study: Greece } \\
\hline \multicolumn{7}{|c|}{ Panel 1: Treatment group } \\
\hline VC funding & 188 & 884.87 & 0.00 & 158.67 & 0.00 & $10,193.35$ \\
\hline Total Assets & 37 & 28.44 & 0.01 & 26.88 & 19.78 & 131.34 \\
\hline LCF amount (1 yr) & 37 & 0.47 & -1.95 & -0.23 & 0.00 & 0.00 \\
\hline Age & 182 & 5.67 & 0.00 & 7.87 & 7.00 & 24.00 \\
\hline \multicolumn{7}{|c|}{ Panel 2: Control group } \\
\hline VC funding & 2452 & $2,285.68$ & 0.00 & 309.59 & 0.00 & $61,000.00$ \\
\hline Total Assets & 417 & 113.85 & 0.00 & 35.80 & 3.24 & 811.39 \\
\hline LCF amount (1 yr) & 418 & 6.22 & -106.86 & -0.85 & 0.00 & 0.00 \\
\hline Age & 2416 & 5.84 & -1.00 & 7.73 & 7.00 & 24.00 \\
\hline \multicolumn{7}{|c|}{ Case Study: Croatia } \\
\hline \multicolumn{7}{|c|}{ Panel 1: Treatment group } \\
\hline VC funding & 83 & $1,192.69$ & 0.00 & 211.24 & 0.00 & $10,000.00$ \\
\hline Total Assets & 57 & 5.39 & 0.00 & 5.46 & 4.22 & 18.42 \\
\hline LCF amount (1 yr) & 57 & 0.68 & -4.86 & -0.15 & 0.00 & 0.00 \\
\hline Age & 83 & 7.17 & 0.00 & 12.66 & 15.00 & 24.00 \\
\hline \multicolumn{7}{|c|}{ Panel 2: Control group } \\
\hline VC funding & 589 & $22,690.12$ & 0.00 & $1,150.09$ & 0.00 & $550,000.50$ \\
\hline Total Assets & 145 & $1,017.14$ & 0.03 & 175.45 & 2.14 & $7,636.00$ \\
\hline LCF amount (1 yr) & 144 & 1.32 & -14.98 & -0.22 & 0.00 & 0.00 \\
\hline Age & 578 & 6.62 & -1.00 & 10.04 & 10.00 & 51.00 \\
\hline \multicolumn{7}{|c|}{ Case Study: Hungary (2001) } \\
\hline \multicolumn{7}{|c|}{ Panel 1: Treatment group } \\
\hline VC funding & 474 & $1,933.31$ & 0.00 & 205.30 & 0.00 & $34,007.89$ \\
\hline Total Assets & 58 & 4.82 & 0.02 & 4.55 & 2.47 & 18.59 \\
\hline LCF amount (1 yr) & 58 & 0.53 & -2.83 & -0.14 & 0.00 & 0.00 \\
\hline Age & 474 & 5.44 & 0.00 & 9.68 & 9.50 & 25.00 \\
\hline \multicolumn{7}{|c|}{ Panel 2: Control group } \\
\hline VC funding & 1006 & $1,467.05$ & 0.00 & 274.18 & 0.00 & $27,067.64$ \\
\hline Total Assets & 194 & 83.51 & 0.03 & 38.99 & 5.30 & 483.54 \\
\hline LCF amount (1 yr) & 194 & 0.91 & -8.17 & -0.18 & 0.00 & 0.00 \\
\hline Age & 1006 & 5.65 & 0.00 & 11.27 & 11.00 & 25.00 \\
\hline \multicolumn{7}{|c|}{ Case Study: Hungary (2012) } \\
\hline \multicolumn{7}{|c|}{ Panel 1: Treatment group } \\
\hline VC funding & 844 & $1,482.59$ & 0.00 & 182.18 & 0.00 & $34,007.89$ \\
\hline Total Assets & 208 & 3.47 & 0.00 & 2.42 & 1.15 & 18.59 \\
\hline LCF amount (1 yr) & 203 & 0.31 & -2.83 & -0.06 & 0.00 & 0.00 \\
\hline Age & 826 & 5.61 & -1.00 & 7.10 & 6.00 & 25.00 \\
\hline
\end{tabular}




\begin{tabular}{|c|c|c|c|c|c|c|}
\hline Variable & Obs & Std. Dev. & Min & Mean & Median & Max \\
\hline \multicolumn{7}{|c|}{ Panel 2: Control group } \\
\hline VC funding & 1475 & $14,450.22$ & 0.00 & 628.65 & 0.00 & $550,000.50$ \\
\hline Total Assets & 295 & 883.49 & 0.00 & 147.32 & 1.76 & $7,636.00$ \\
\hline LCF amount (1 yr) & 294 & 17.48 & -299.00 & -1.32 & 0.00 & 0.00 \\
\hline Age & 1431 & 6.23 & -1.00 & 8.16 & 7.00 & 51.00 \\
\hline \multicolumn{7}{|c|}{ Case Study: Lithuania } \\
\hline \multicolumn{7}{|c|}{ Panel 1: Treatment group } \\
\hline VC funding & 80 & $1,207.40$ & 0.00 & 211.37 & 0.00 & $9,552.92$ \\
\hline Total Assets & 27 & 22.03 & 0.46 & 14.20 & 2.26 & 77.86 \\
\hline LCF amount (1 yr) & 27 & 0.32 & -1.63 & -0.10 & 0.00 & 0.00 \\
\hline Age & 80 & 4.92 & 4.00 & 13.90 & 14.00 & 23.00 \\
\hline \multicolumn{7}{|c|}{ Panel 2: Control group } \\
\hline VC funding & 506 & $1,868.92$ & 0.00 & 357.28 & 0.00 & $27,067.64$ \\
\hline Total Assets & 59 & 34.51 & 0.21 & 23.69 & 5.27 & 108.46 \\
\hline LCF amount (1 yr) & 59 & 1.11 & -8.17 & -0.23 & 0.00 & 0.00 \\
\hline Age & 506 & 5.16 & 0.00 & 10.40 & 10.00 & 23.00 \\
\hline
\end{tabular}

Notes: Summary statistics for the variables, as defined in Table 11. Differentiated between case study and treatment (Panel 1) and control group (Panel 2). 


\begin{tabular}{|c|c|c|c|c|c|}
\hline & & & $\begin{array}{l}\text { Event study } \\
\text { g(VC fundir }\end{array}$ & & \\
\hline & GR & HR & HU (2001) & HU (2012) & LT \\
\hline $\mathrm{t}-4$ & 1.753 & - & - & -0.148 & - \\
\hline$t-3$ & 0.270 & - & - & 0.049 & $-1.533 *$ \\
\hline $\mathrm{t}-2$ & -0.933 & -0.002 & 0.806 & 0.635 & 0.398 \\
\hline $\mathrm{t}$ & -0.448 & 0.383 & 0.914 & -0.098 & 0.064 \\
\hline $\mathrm{t}+1$ & - & -0.318 & 0.758 & -0.161 & 0.664 \\
\hline$t+2$ & - & 2.049 & 0.461 & -0.179 & 0.300 \\
\hline$t+3$ & - & -0.725 & 0.345 & - & -1.904 \\
\hline $\mathrm{t}+4$ & - & 0.741 & 0.627 & - & -1.180 \\
\hline Escape clause & omitted & omitted & 0.025 & omitted & omitted \\
\hline LCF years & 0.037 & 0.075 & -0.004 & 0.024 & $0.102 *$ \\
\hline LCB years & omitted & omitted & omitted & omitted & omitted \\
\hline LCF limit & -0.558 & $1.928 * *$ & 0.290 & -1.009 & $-1.584 *$ \\
\hline CIT & $-0.192 * *$ & $-0.227 *$ & $0.095^{*}$ & 0.004 & 0.196 \\
\hline$\Delta \mathrm{CIT}$ & $0.190 * *$ & $0.218 * * *$ & $-0.075^{*}$ & -0.067 & $-0.160 *$ \\
\hline CGT & 3.224 & -5.824 & $2.248^{*}$ & -1.287 & 1.818 \\
\hline DIT & $-3.210 * * *$ & -4.613 & -1.296 & -3.381 & -3.354 \\
\hline GDP per capita & -0.000 & 0.000 & 0.000 & 0.000 & -0.000 \\
\hline GDP growth & 0.003 & 0.044 & -0.007 & 0.007 & 0.007 \\
\hline Unemployment & -0.035 & $0.139 * *$ & -0.035 & -0.036 & -0.019 \\
\hline Inflation & 0.133 & $-0.100 *$ & 0.025 & $-0.076 * * *$ & -0.006 \\
\hline EIF amount & $-0.002 * *$ & $0.017 * * *$ & $-0.010 * *$ & $-0.010 * *$ & -0.002 \\
\hline EIF number & -0.000 & $-0.001 * * *$ & 0.000 & 0.000 & 0.000 \\
\hline Lagged Public PE & $0.000 *$ & -0.000 & - & 0.000 & - \\
\hline Firm FE & Yes & Yes & Yes & Yes & Yes \\
\hline Year FE & Yes & Yes & Yes & Yes & Yes \\
\hline \# Observations & 2,640 & 672 & 1,480 & 2,319 & 586 \\
\hline Adj. R-squared & 0.054 & 0.070 & 0.093 & 0.063 & 0.068 \\
\hline
\end{tabular}

Notes: Dependent variable: Firm-level VC funding volume. Results of the event study, difference between treatment and control group. " $\mathrm{t}$ ": time of change in legislation. " $\mathrm{t}-\mathrm{x}$ ": leads. " $\mathrm{t}+\mathrm{x}$ ": lags. Controls as indicated. Definition of variables: Table $11 . *, * *$, and $* * *$ indicate significance at the 10,5 , and $1 \%$ level. Standard errors: Clustered at country level. "Omitted": Variable was omitted from the regression due to multi-collinearity. 
Table 28: DiD results, restriction category, case studies (appendix)

\section{I - Restriction category}

$\log (\mathrm{VC}$ funding)

\begin{tabular}{lccccc}
\hline & GR & HR & HU (2001) & HU (2012) & LT \\
\hline Restriction category & -0.716 & 0.304 & $0.522^{* *}$ & -0.253 & 0.055 \\
\hline Escape clause & omitted & -0.349 & 0.017 & 0.020 & omitted \\
LCF years & 0.030 & 0.049 & -0.013 & 0.022 & 0.073 \\
LCB years & omitted & omitted & omitted & omitted & omitted \\
LCF limit & -0.266 & $1.886^{* *}$ & 0.276 & $-1.084 * * *$ & -1.526 \\
CIT & -0.156 & $-0.237^{* * *}$ & 0.079 & 0.015 & 0.157 \\
$\Delta$ CIT & 0.170 & $0.206^{* * *}$ & -0.071 & -0.078 & $-0.143^{* *}$ \\
CGT & 3.797 & $-5.973^{* * *}$ & $2.167^{*}$ & -2.021 & 1.749 \\
DIT & $-3.639^{* *}$ & 0.520 & -1.497 & -2.590 & -1.888 \\
GDP per capita & $-0.000^{* *}$ & $0.000^{* *}$ & 0.000 & 0.000 & -0.000 \\
GDP growth & 0.033 & 0.025 & 0.003 & 0.016 & 0.019 \\
Unemployment & -0.037 & $0.123^{*}$ & -0.012 & -0.025 & -0.014 \\
Inflation & 0.174 & $-0.098^{* *}$ & 0.028 & $-0.072 * *$ & -0.004 \\
EIF amount & $-0.002^{* * *}$ & $0.016^{* *}$ & $-0.010^{* *}$ & $-0.010 *$ & -0.004 \\
EIF number & -0.000 & $-0.001^{* * *}$ & $0.000^{* *}$ & 0.000 & 0.000 \\
Lagged Public PE & $0.000^{* *}$ & -0.000 & - & 0.000 & - \\
\hline Firm FE & Yes & Yes & Yes & Yes & Yes \\
Year FE & Yes & Yes & Yes & Yes & Yes \\
\hline \# Observations & 2,640 & 672 & 1,480 & 2,319 & 586 \\
Adj. R-squared & 0.054 & 0.070 & 0.095 & 0.063 & 0.069 \\
\hline
\end{tabular}

Notes: Results linear DiD regressions of treatment dummy on the logarithm of VC funding volume received. Treatment dummy equals 1 in the year of change in legislation and all following years, and zero otherwise. Controls as indicated. Definition of variables: Table 11 (appendix). *,**, and $* * *$ indicate significance at the 10, 5, and $1 \%$ level. Standard errors: Clustered at country level. "Omitted": Variable was omitted from the regression due to multi-collinearity. 


\section{References}

Bernasconi, M., Marenzi, A., \& Pagani, L. (2005). Corporate financing decisions and non-debt tax shields: Evidence from Italian experiences in the 1990s. International Tax and Public Finance, 12(6), 741-773. https://doi.org/10.1007/s10797-005-2914-1

Bernoth, K., \& Colavecchio, R. (2014). The macroeconomic determinants of private equity investment: A European comparison. Applied Economics, 46(11), 1170-1183. https://doi.org/10.1080/00036846.2013.866306

Bertoni, F., Croce, A., \& Guerini, M. (2015). Venture capital and the investment curve of young high-tech companies. Journal of Corporate Finance, 35(217485), 159-176. https://doi.org/10.1016/j.jcorpfin.2015.08.012

Bethmann, I., Jacob, M., \& Müller, M. A. (2018). Tax Loss Carrybacks: Investment stimulus versus misallocation. Accounting Review, 93(4), 101-125. https://doi.org/10.2308/accr-51956

Bührle, A. T., \& Spengel, C. (2020). Tax Law and the Transfer of Losses: A European Overview and Categorization. Intertax, 48(6/7), 564-581.

Carpenter, R. E., \& Petersen, B. C. (2002a). Capital Market Imperfections, High-Tech Investment, and New Equity Financing. The Economic Journal, 112(477), F54-F72.

Carpenter, R. E., \& Petersen, B. C. (2002b). Is the Growth of Small Firms Constrained By Internal Finance? The Review of Economics and Statistics, 84(May), 298-309.

Chabé-Ferret, S. (2017). Should We Combine Difference In Differences with Conditioning on Pre-Treatment Outcomes? Retrieved from https://www.tsefr.eu/sites/default/files/TSE/documents/doc/wp/2017/wp_tse_824.pdf

Cherif, M., \& Gazdar, K. (2011). What drives venture capital investments in Europe? New results from a panel data analysis. Journal of Applied Business and Economics, 12(3), 122-139.

Chiang, W. C., Stammerjohan, W., \& Englebrecht, T. D. (2014). Pricing target NOLs in mergers and acquisitions from the participating firms' perspective. Advances in Accounting, 30(1), 32-42. https://doi.org/10.1016/j.adiac.2014.04.003

Coad, A., Segarra, A., \& Teruel, M. (2016). Innovation and firm growth: Does firm age play a role? Research Policy, 45(2), 387-400. https://doi.org/10.1016/j.respol.2015.10.015

Cooper, M., \& Knittel, M. (2006). Partial Loss Refundability : How Are Corporate Tax Losses Used? National Tax Journal, 59(3), 651-663.

Cooper, M., \& Knittel, M. J. (2010). The implications of tax asymmetry for U.S. corporations. National Tax Journal, 63(1), 33-62.

Cosh, A., Cumming, D., \& Hughes, A. (2009). Outside entrepreneurial capital. Economic Journal, 119(540), 1494-1533. https://doi.org/10.1111/j.1468-0297.2009.02270.x

Croce, A., D’Adda, D., \& Ughetto, E. (2015). Venture capital financing and the financial distress risk of portfolio firms: How independent and bank-affiliated investors differ. Small Business Economics, 44(1), 189-206. https://doi.org/10.1007/s11187-014-9582-4

Croce, A., Martí, J., \& Murtinu, S. (2013). The impact of venture capital on the productivity growth of European entrepreneurial firms: "Screening" or "value added" effect? Journal of Business Venturing, 28(4), 489510. https://doi.org/10.1016/j.jbusvent.2012.06.001

Da Rin, M., Di Giacomo, M., \& Sembenelli, A. (2011). Entrepreneurship, firm entry, and the taxation of corporate income: Evidence from Europe. Journal of Public Economics, 95(9-10), 1048-1066. https://doi.org/10.1016/j.jpubeco.2010.06.010

Da Rin, M., Hellmann, T., \& Puri, M. (2013). A Survey of Venture Capital Research. Handbook of the Economics of Finance (Vol. 2). Elsevier B.V. https://doi.org/10.1016/B978-0-44-453594-8.00008-2

Da Rin, M., Nicodano, G., \& Sembenelli, A. (2006). Public policy and the creation of active venture capital markets. Journal of Public Economics, 90(8-9), 1699-1723. https://doi.org/10.1016/j.jpubeco.2005.09.013

Dreßler, D., \& Overesch, M. (2013). Investment impact of tax loss treatment-empirical insights from a panel of multinationals. International Tax and Public Finance, 20(3), 513-543. https://doi.org/10.1007/s10797012-9240-1 
Edwards, A., \& Todtenhaupt, M. (2020). Capital Gains Taxation and Funding for Start-Ups. Journal of Financial Economics, 138(2), 549-571.

Félix, E. G. S., Pires, C. P., \& Gulamhussen, M. A. (2013). The Determinants of Venture Capital in Europe Evidence Across Countries. Journal of Financial Services Research, 44(3), 259-279. https://doi.org/10.1007/s10693-012-0146-y

Grilli, L., \& Murtinu, S. (2014). Government, venture capital and the growth of European high-tech entrepreneurial firms. Research Policy, 43(9), 1523-1543. https://doi.org/10.1016/j.respol.2014.04.002

Guerini, M., \& Quas, A. (2016). Governmental venture capital in Europe: Screening and certification. Journal of Business Venturing, 31(2), 175-195. https://doi.org/10.1016/j.jbusvent.2015.10.001

Haltiwanger, J., Jarmin, R. S., \& Miranda, J. (2013). Who creates jobs? Small versus large versus young. Review of Economics and Statistics, 95(2), 347-361. https://doi.org/10.1162/REST_a_00288

Haring, M., Niemann, R., \& Runger, S. (2012). Corporate Financial Policy and Individual Income Taxation in Austria. Betriebswirtschaft/Business Administration Review, 72(6), 473-486. Retrieved from http://search.proquest.com/docview/1322238610?accountid=17248

Haufler, A., Norbäck, P. J., \& Persson, L. (2014). Entrepreneurial innovations and taxation. Journal of Public Economics, 113(December 2013), 13-31. https://doi.org/10.1016/j.jpubeco.2014.03.002

Haw, I. M., Pastena, V., \& Lilien, S. (1987). The Association between Market-Based Merger Premiums and Firms' Financial Position Prior to Merger. Journal of Accounting, Auditing \& Finance, 2(1), $24-42$. https://doi.org/10.1177/0148558X8700200103

Hayn, C. (1989). Tax attributes as determinants of shareholder gains in corporate acquisitions. Journal of Financial Economics, 23(1), 121-153. https://doi.org/10.1016/0304-405X(89)90008-1

Hege, U., Palomino, F., \& Schwienbacher, A. (2009). Venture Capital Performance: The Disparity Between Europe and the United States. Finance (Vol. 30). https://doi.org/10.3917/fina.301.0007

Henning, S. L., Shaw, W. H., \& Stock, T. (2000). The Effect of Taxes on Acquisition Price and Transaction Structure. Journal of the American Taxation Association, 22, 1-17. https://doi.org/10.2308/jata.2000.22.s1.18

Henrekson, M., \& Sanandaji, T. (2011). Entrepreneurship and the theory of taxation. Small Business Economics, 37(2), 167-185. https://doi.org/10.1007/s1118700992422

Hoenig, M. (2014). Trafficking in Net Operating Losses: What's So Bad. Tax Notes Special Report, 149, 919939. Retrieved from https://taxprof.typepad.com/files/145tn0919.pdf

Iacus, S. M., King, G., \& Porro, G. (2011). Multivariate matching methods that are monotonic imbalance bounding. Journal of the American Statistical Association, 106(493), 345-361. https://doi.org/10.1198/jasa.2011.tm09599

Iacus, S. M., King, G., \& Porro, G. (2012). Causal inference without balance checking: Coarsened exact matching. Political Analysis, 20(1), 1-24. https://doi.org/10.1093/pan/mpr013

Jeng, L. A., \& Wells, P. C. (2000). The determinants of venture capital funding: evidence across countries. Journal of Corporate Finance, 6(3), 241-289. https://doi.org/https://doi.org/10.1016/S09291199(00)00003-1

Keuschnigg, C., \& Bo Nielsen, S. (2003). Taxes and Venture Capital Support. European Finance Review, 7(3), 515-539. https://doi.org/10.1023/b:eufi.0000022144.17225.35

Keuschnigg, C., \& Nielsen, S. B. (2004). Start-ups, venture capitalists, and the capital gains tax. Journal of Public Economics, 88(5), 1011-1042. https://doi.org/10.1016/S0047-2727(03)00046-X

KPMG. (2020). Venture Pulse Q4 2019. Global analysis of venture funding. Retrieved from https://assets.kpmg/content/dam/kpmg/xx/pdf/2020/01/venture-pulse-q4-2019-global.pdf

Krämer, R. (2015). Taxation and Capital Structure Choice: The Role of Ownership. Scandinavian Journal of Economics, 117(3), 957-982. https://doi.org/10.1111/sjoe.12107

Langenmayr, D., \& Lester, R. (2018). Taxation and corporate risk-taking. Accounting Review, 93(3), $237-266$. https://doi.org/10.2308/accr-51872

Lawless, M. (2014). Age or size? Contributions to job creation. Small Business Economics, 42(4), 815-830. https://doi.org/10.1007/s11187-013-9513-9 
Li, Y., \& Zahra, S. A. (2012). Formal institutions, culture, and venture capital activity: A cross-country analysis. Journal of Business Venturing, 27(1), 95-111. https://doi.org/10.1016/j.jbusvent.2010.06.003

Ljungqvist, A., Zhang, L., \& Zuo, L. (2017). Sharing Risk with the Government: How Taxes Affect Corporate Risk Taking. Journal of Accounting Research, 55(3), 669-707. https://doi.org/10.1111/1475-679X.12157

Lüken, J. (2014). Innovationen und asymmetrische Besteuerung. Wiesbaden: Springer Gabler. https://doi.org/10.1007/978-3-658-13600-0

Macmillan, I. C., Siegel, R., \& Narasimha, P. N. S. (1985). Criteria used by venture capitalists to evaluate new venture proposals. Journal of Business Venturing, 1(1), 119-128. https://doi.org/10.1016/08839026(85)90011-4

Mehrmann, A., \& Sureth-Sloane, C. (2017). Tax Loss Offset Restrictions and Biased Perception of Risky Investments. Retrieved from https://papers.ssrn.com/sol3/papers.cfm?abstract_id=3046543

Merz, J., \& Overesch, M. (2016). Profit shifting and tax response of multinational banks. Journal of Banking and Finance, 68, 57-68. https://doi.org/10.1016/j.jbankfin.2016.03.015

Moore, N. H., \& Pruitt, S. W. (1987). The Market Pricing of Net Operating Loss Carryforwards: Implications of the Tax Motivations of Mergers. Journal of Financial Research, 10(2), 153-161.

Niemann, R. (2004). Asymmetric Taxation and Cross-Border Investment Decisions. Retrieved from https://ideas.repec.org/p/ces/ceswps/_1219.html

Nijhawan, A. (2015). When Is " Loss Trading " Permissible? A Purposive Analysis of Subsection 111 ( 5 ). In Canadian Tax Foundation Conference Report (pp. 1-26).

Petty, J. S., \& Gruber, M. (2011). "In pursuit of the real deal”. A longitudinal study of VC decision making. Journal of Business Venturing, 26(2), 172-188. https://doi.org/10.1016/j.jbusvent.2009.07.002

Plummer, E., \& Robinson, J. R. (1990). Capital Market Evidence of Windfalls From the Acquisition of Tax Carryovers. National Tax Journal, 43(4), 481-489. Retrieved from https://www.jstor.org/stable/41788867

Poitevin, M. (2003). Effects of the Fiscal Treatment of Tax Losses on the Efficiency of Markets and the Incidence of Mergers. Retrieved from https://journals.openedition.org/economiepublique/441

Rechbauer, M. (2017). Identifying Firms 'Tax Loss Carry-Forward Status - The Accuracy of Database-Driven Methods. Retrieved from http://www.arqus.info/mobile/paper/arqus_201.pdf

Schmidheiny, K., \& Siegloch, S. (2019). On Event Study Designs and Distributed-Lag Models: Equivalence , Generalization and Practical Implications (IZA Discussion Paper No. 12079).

Schwienbacher, A. (2008). Innovation and Venture Capital Exits. The Economic Journal, 118(553), $1888-1916$.

Shepherd, B. (2016). The Gravity Model of International Trade: A User Guide (An updated version). United Nations publication. Retrieved from https://www.unescap.org/sites/default/files/GravityUserGuideREVISED-02.pdf

Silva, J. M. C. S., \& Tenreyro, S. (2006). The log of gravity. The Review of Economics and Statistics, 88(4), 641-658.

Sureth-Sloane, C., \& Vollert, P. (2009). Verschärfung der Verlustabzugsbeschränkung durch § 8c KStG und deren Einfluss auf den Erwerb von Anteilen an Kapitalgesellschaften. Retrieved from https://www.econstor.eu/bitstream/10419/30870/1/614991676.pdf

Van Praag, C. M., \& Versloot, P. H. (2007). What is the value of entrepreneurship? A review of recent research. Small Business Economics, 29(4), 351-382. https://doi.org/10.1007/s11187-007-9074-X

Zwick, E. (2021). The Costs of Corporate Tax Complexity. American Economic Review, (Forthcoming).

Databases:

InvestEurope (2019). Annual European private equity activity statistics, update April 2019. Available upon request from www.investeurope.eu/research (31.07.2019).

EIF (2020). EIF for SMEs. Small and medium-sized enterprises supported by the European Union. Freely available from https://www.eif4smes.com/ (30.10.2020). 
Download ZEW Discussion Papers from our ftp server:

http://ftp.zew.de/pub/zew-docs/dp/

or see:

https://www.ssrn.com/link/ZEW-Ctr-Euro-Econ-Research.html

https://ideas.repec.org/s/zbw/zewdip.html

$$
\text { // }
$$

IMPRINT

ZEW - Leibniz-Zentrum für Europäische Wirtschaftsforschung GmbH Mannheim

ZEW - Leibniz Centre for European

Economic Research

L 7,1 68161 Mannheim · Germany

Phone +49621 1235-01

info@zew.de·zew.de

Discussion Papers are intended to make results of ZEW research promptly available to other economists in order to encourage discussion and suggestions for revisions. The authors are solely responsible for the contents which do not necessarily represent the opinion of the ZEW. 